\title{
The effect of oscillatory flow on nucleation kinetics of butyl paraben
}

Huaiyu Yang ${ }^{1}, \mathrm{Xi} \mathrm{Yu}^{2}$, Vishal Raval ${ }^{1}$, Yassir Makkawi ${ }^{3}$, Alastair Florence ${ }^{1^{*}}$

1. CMAC, Strathclyde Institute of Pharmacy and Biomedical Sciences, University of Strathclyde, Glasgow, UK

2. European Bioenergy Research Institute (EBRI), School of Engineering and Applied Science, Aston University, Birmingham, UK

3. Chemical Engineering Department, American University of Sharjah, Sharjah, United Arab Emirates.

* corresponding author: alastair.florence@strath.ac.uk

\section{Abstract}

More than 165 induction times of butyl paraben - ethanol solution in batch moving fluid oscillation baffled crystallizer with various amplitudes $(1-9 \mathrm{~mm})$ and frequencies $(1.0-9.0$ $\mathrm{Hz}$ ) have been determined to study the effect of COBR operating conditions on nucleation. The induction time decreases with increasing amplitude and frequency at power density below about $500 \mathrm{~W} / \mathrm{m}^{3}$, however, a further increase of the frequency and amplitude leads to an increase of the induction time. The interfacial energies and pre-exponential factors in both homogeneous and heterogeneous nucleation are determined by Classical Nucleation Theory at oscillatory frequency $2.0 \mathrm{~Hz}$ and amplitudes of $3 \mathrm{~mm}$ or $5 \mathrm{~mm}$ both with and without net flow. To capture the shear rate conditions in oscillatory flow crystallisers, a Large Eddy Simulation approach in Computational Fluid Dynamics framework is applied. Under ideal conditions the shear rate distribution shows spatial and temporal periodicity and radially symmetry. The spatial distributions of the shear rate indicate an increase of average and maximum values of the shear rate with increasing amplitude and frequency. In 
continuous operation, net flow enhances the shear rate at most time points, promoting nucleation. The mechanism of the shear rate influence on nucleation is discussed.

\section{Introduction}

Crystallization is a key process for the purification and isolation of active pharmaceutical ingredients, many small organic and fine chemical compounds, and is most commonly implemented as a batch operation. With the potential advantages [1, 2] of less down time, more efficient use of energy and space, better heat transfer and mixing and lower risk of process failures, continuous crystallization is of increasing interest for pharmaceutical manufacturing [3]. Operating continuous multiphase processes for extended periods can also pose challenges including instabilities introduced by variations in temperature and encrustation. Continuous crystallization has been investigated in different platforms recently [4], i.e. mixed-suspension mixed-product-removal (MSMPR) $[5][6][7,8]$ and plug flow reactor [9] including continuous oscillatory flow crystallisers (COFC) $[1,10,11]$. Primary nucleation is a complex poorly understood process and is a critical transformation in controlling the crystal form, number and size of particles in a crystallization process. It is therefore essential to understand the process conditions within a continuous reactor under which primary nucleation can occur or can be avoided.

The influence of shear rate on crystallization has been reported in many systems. For example the polymorphic form of carbamazepine can be altered depending on whether the crystallized solution is quiescent or exposed to high shear [12]. Stirring rates effect the metastable zone widths of L-glutamic acid [13] carbamazepine [12] and m-hydroxybenzoic acid [14]. The effect of shear rate on nucleation is however complex considering the 
variational shear distribution of the solution in a crystallizer. Computational fluid dynamics (CFD) models, particularly Large Eddy Simulation (LES) models [15, 16], are powerful tools to study transient flow behaviour (e.g. the shear) in crystallizers [17]. Several computational fluid dynamics simulations have been performed to understand velocity and shear conditions in oscillatory flow reactors. Jian [18] analysed velocity fields (e.g. surface and cycle averaged velocity and velocity ratios), and the velocity ratios of axial to radial velocity components in the oscillatory baffled crystallizer are largely independent of the column diameter. Manninen [19] employed two parameters including the axial dispersion coefficient and the ratio of axial and transverse velocities in the CFD simulations and $\mathrm{Ni}$ [20] showed 3-D numerical simulation of oscillatory flow (e.g. flow pattern and velocity vector) in a baffled column and validated the results with experimental observations using digital particle image velocimetry measurements. However the quantitative analysis and spatial distributions of shear rate in an oscillatory flow crystallizer have not been reported.

Butyl paraben (butyl 4-hydroxybenzoate) shown in Figure 1, as with other parabens are generally considered to be safe [21] and are widely used in pharmaceutical products and cosmetics [22]. Butyl paraben has only one known polymorph [23] with a relative low melting point $340.5 \mathrm{~K}[24]$. In ethanol, butyl paraben has a very high solubility $[25,26]$ and usually forms prismatic shape crystals $[27,28]$. A relative low solid-liquid interfacial energy $[23,28]$ was determined, from nucleation studies of butyl paraben in ethanol under equal stirring rate conditions. In this work, induction time experiments have been performed in a batch moving fluid oscillatory baffled crystallizer (MFOBC) and continuous oscillatory flow crystallizer (COFC) to investigate the impact of supersaturation and shear conditions (oscillatory amplitudes, frequencies and net flow rates) on the nucleation kinetics of this 
system. Classical Nucleation Theory has been applied to estimate and analyse the interfacial energy and pre-exponential factor for butyl paraben - ethanol system and the effect of shear rate quantified. The spatial shear rate distributions have been estimated using CFD determined at different times during the period of oscillation. The shear rate distributions are dependent on the sinusoidal velocity of the piston movement (a period of piston velocity is $T_{V}$, as well as the net flow rate. The average, middle and maximum shear rates have been compared at time of $0.25 T_{V}, 0.5 T_{V}, 0.75 T_{V}$, and $T_{V}$ with induction time results in both the MFOBC and COFC. Before nucleation the distributions of the clusters in the solution influenced by different shear rates appears to result in the different nucleation behaviours.

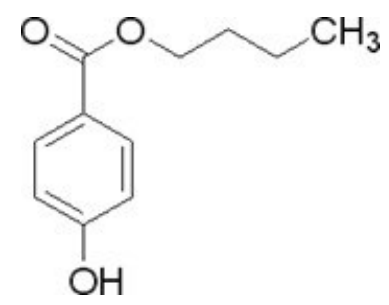

Figure 1. Molecular structure of butyl paraben

\section{THEORY}

Interfacial energy and pre-exponential factor

In Classical Nucleation Theory, the free energy change upon nucleation is the free energy change of bringing molecules from the supersaturated solution into the cluster, subtracting the interfacial energy of the cluster. Under the assumption of a spherical shape the derivation leads to the basic equation, which defines the nucleation rate 


$$
J=A \exp \left(-\frac{\Delta G_{c}}{k T}\right)=A \exp \left(-\frac{16 \pi \sigma^{3} v_{m}^{2}}{3 k^{3} T^{3}(\ln S)^{2}}\right)
$$

where $\sigma$ is the solid-liquid interfacial energy, $v_{m}$ is the volume of one solute molecule, $A$ is the pre-exponential factor, $\mathrm{k}$ is the Boltzmann constant, $\mathrm{T}$ is nucleation temperature, $\mathrm{S}$ is the supersaturation and $\Delta \mu$ is the difference in chemical potential between the solute in solution and in the crystalline bulk phase, which is usually estimated by actual and equilibrium solute mole fraction in the solution $\Delta \mu=k T \ln S \approx k T \ln \frac{x}{x^{*}}$. The nucleus is defined as a crystalline particle of size sufficient for growth to be thermodynamically favourable.

The induction time, $t_{\text {ind }}$, is the time period from the establishment of the supersaturated state to the first observation of crystals in the solution and is assumed to contain three parts 28: a relaxation time or transient period $t_{r}$, the time required for formation of a stable nucleus, $t_{n}$, and the time for a nucleus to grow to a detectable size, $t_{g}$. Usually it is assumed that the relaxation time and the growth time are negligible and that the induction time is inversely proportional to the nucleation rate in nucleation in the solution of volume V:

$$
\begin{gathered}
\ln t_{\text {ind }}=-\ln J_{H O N} \mathrm{~V}=-\ln A_{H O N} \mathrm{~V}+\frac{B}{T^{3}(\ln S)^{2}} \\
B=\frac{16 \pi \sigma_{H O N}^{3} v_{m}^{2}}{3 k^{3}}
\end{gathered}
$$

Induction time experiments are usually evaluated by plotting $\ln t_{\text {ind }}$, versus $T^{-3}(\ln S)^{-2}$, for determination of the interfacial free energy $\sigma$ from the slope, B. The pre-exponential factor, $A$, is positively proportional to the attachment frequency and negatively proportional to the energy barrier for diffusion [29] or desolvation [30]. 
In some cases, there is a tendency for a decreasing slope, $B$, at decreasing supersaturation, which could indicate a mechanism transition [31] from homogeneous nucleation (HON) to heterogeneous nucleation (HEN),

$$
J_{H E N}=A_{H E N} \exp \left(-\frac{16 \pi \sigma_{H E N}^{3} v_{m}^{2}}{3 k^{3} T^{3}(\ln S)^{2}}\right)
$$

and the activity coefficient of interfacial energy in heterogeneous nucleation can be determined by comparing the interfacial energy in homogeneous nucleation with that in heterogeneous nucleation and an activity coefficient of interfacial energy $(0<\gamma=$ $\sigma_{H E N} / \sigma_{H O N}<1$ ) is employed in Equ. (1).

CFD model (Subgrid-scale model)

A large eddy simulation (LES) model is able to describe the hydrodynamics (e.g. velocity and shear rate) of the liquid phase within both reactors. The model was solved using the computational fluid dynamic (CFD) software ANSYS FLUENT Version 14 [32]

The main model equations used to simulate the non-reactive flow in the $\mathrm{OBC}$ are:

Continuity equations:

$$
\frac{\partial\left(\rho_{l}\right)}{\partial t}+\nabla\left(\rho_{l} \vec{u}_{l}\right)=0
$$

Momentum equations:

$$
\frac{\partial\left(\rho_{l} \vec{u}_{l}\right)}{\partial t}+\nabla\left(\rho_{l} \vec{u}_{l} \vec{u}_{l}\right)=-\nabla P+\nabla \overline{\bar{\tau}}_{l}+\rho_{l} \vec{g}
$$

where: 


$$
\begin{gathered}
\overline{\bar{\tau}}_{l}=\left(\lambda_{l}-\frac{2}{3} \mu_{l}\right)\left(\nabla \cdot \vec{u}_{l}\right) \overline{\bar{I}}+2 \mu_{l} \overline{\bar{S}}_{l} \\
\overline{\bar{S}}_{l}=\frac{1}{2}\left(\nabla \vec{u}_{l}+\left(\nabla \vec{u}_{l}\right)^{T}\right)
\end{gathered}
$$

where $l$ represents liquid phase, $\rho_{l}$ is density of liquid, $\vec{u}_{l}$ is velocity of liquid, $\mu_{l}$ is kinetic viscosity of the liquid, $\overline{\bar{S}}$ is strain rate of liquid, $\overline{\bar{\tau}}_{l}$ is shear stress of liquid, $\vec{g}$ is gravity of liquid and $P$ is pressure of liquid. $\lambda_{1}$ is bulk viscosity of liquid, $\overline{\bar{I}}$ is unit vector, $\nabla \overrightarrow{\mathrm{u}}_{1}$ is the spatial derivative of velocity vector, $\left(\nabla \overrightarrow{\mathrm{u}}_{1}\right)^{\mathrm{T}}$ is the transpose of $\nabla \overrightarrow{\mathrm{u}}_{1}$.

The deviatoric part of the subgrid-scale stress tensor is modelled using a compressible form of the Smagorinsky model:

$$
\tau_{i j}-\frac{1}{3} \tau_{k k} \delta_{i j}=-2 \mu_{t}\left(S_{i j}-\frac{1}{3} S_{k k} \delta_{i j}\right)
$$

The eddy viscosity is modelled as

$$
\mu_{\mathrm{t}}=\rho \mathrm{L}_{\mathrm{s}}^{2}|\overline{\mathrm{S}}|
$$

Where $\bar{S}$ is the rate-of-strain for the resolved scale which is calculated by $|\bar{S}|=\sqrt{2 \bar{S}_{i j} \bar{S}_{\mathrm{ij}}}$ and the mixing length for subgrid scales $L_{s}$ is defined as

$$
L_{s}=\min \left(\kappa d, C_{s} \Delta\right)
$$

where $\mu_{\mathrm{t}}$ is the subgrid-scale of the turbulent viscosity, $\tau_{k k}$ is the isotropic part of the subgrid-scale stresses, $\tau_{\mathrm{ij}}$ is the deviatoric part of the subgrid-scale stress tensor, $S_{i j}$ is rateof-strain tensor for sub-scale, $\bar{s}_{i j}$ is the rate-of-strain tensor for the resolved scale, $\delta_{\mathrm{ij}}$ is Kronecker delta function, $\kappa$ is von Karman constant, $\mathrm{d}$ is the distance to the closest wall and 
$\mathrm{C}_{\mathrm{s}}$ is the Smagorisky constant which value used in this study is $0.2 . \Delta$ is local grid scale, computing according to the volume of the computational cell using $\Delta=\mathrm{V}^{1 / 3}$.

\section{Experimental work}

Butyl paraben (BP) > $99.0 \%$ mass purity was purchased from Aldrich and used without further purification. Ethanol (E) of $99.8 \%$ mass purity was purchased from Aldrich, and distilled water was used.

Induction times for butyl paraben have been determined in the MFOBC and COFC at different levels of supersaturation. Figure 2 a) and b) show the set-up of both platforms used. Only one vertical jacketed glass column was used in the MFOBC connected to a PTFE bellow (piston) via a temperature controlled glass U-bend, and these two sections were separated by a nitrile rubber membrane. Oscillation was generated by a linear motor and Xenus controller operating a PTFE Bellow. One jacketed glass column $700 \mathrm{~mm}$ long comprises 15 cells each with an internal diameter of $16.3 \mathrm{~mm}$ and $25.6 \mathrm{~mm}$ long. Neighbouring cells were separated by anular baffles each with an orifice diameter of $7.6 \mathrm{~mm}$ and a height of $2.5 \mathrm{~mm}$. All of the glass was $1.8 \mathrm{~mm}$ thickness. An FBRM probe and a thermocouple were fixed in the middle of the glass column via probe ports to observe the number of particles in the solution and the temperature of the solution, respectively. For the COFC set up, two identical glass columns were connected with a glass bend mounted horizontally. One end of the first column was connected to the oscillator and the end of the second column was connected to a peristaltic pump (Watson-Marlow 520S) to circulate the solution with a pump head rotation speed 15 and 20 rpm under temperature control back into the first column through the oscillation section (Figure 
2). Oscillation is controlled in the same as the MFOBC. Calibration of the oscillatory amplitudes in the COFC was performed prior to carrying out the experiments.
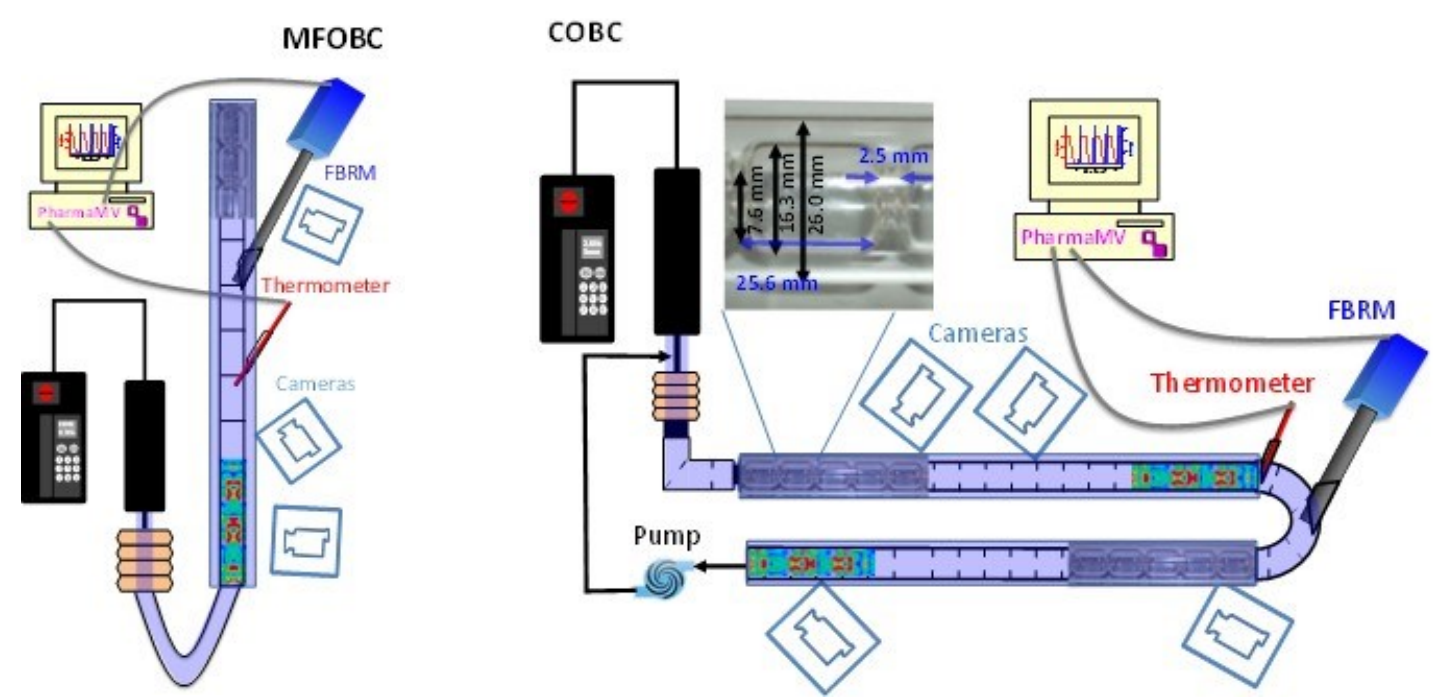

Figure 2 Schematic equipment set up a) MFOBC and b) COFC combined with part of actual glass column photo and part of CFD simulation result.

$200 \mathrm{~mL}$ of butyl paraben in ethanol solution (2.490 g butyl paraben / g ethanol) with saturation temperature of $24.2{ }^{\circ} \mathrm{C}$ was prepared in a $400 \mathrm{ml}$ glass bottle. This was held in a water bath at a constant temperature of $50.0^{\circ} \mathrm{C}$ and stirred by a magnetic stirrer for 60 min to insure that no undissolved paraben was present. The solution was quickly transferred into the MFOBC which was sealed by a fexible membrane. Frequencies in the range 1.0 to 9.0 $\mathrm{Hz}$ and amplitudes from 1 to $9 \mathrm{~mm}$ were applied. In all the experiments, the butyl paraben solution in the MFOBC was heated to $50.0{ }^{\circ} \mathrm{C}$ for 30 minutes before the solution was cooled to $35.0{ }^{\circ} \mathrm{C}$ at a rate of $2.0{ }^{\circ} \mathrm{C}$ per minute. In order to prevent overcooling the sample during rapid cooling to the target temperature, the final temperature reduction was to between $19.0-22.0{ }^{\circ} \mathrm{C}$ at $1.0{ }^{\circ} \mathrm{C}$ per minute. Temperatures were controlled using PharmaMV v4.0 control software which was also used to collect the data from the PAT probes. Eight high resolution web cameras (Manhattan HD 760 Pro) were used at several 
different positions in the crystallizer with images captured every $1 \mathrm{~s}$. The FBRM probe (G400 version), with a measurement range of $0.25-2000 \mu \mathrm{m}$, was operated with a measurement duration of $2 \mathrm{~s}$. Chord length distributions in the range $0-1000 \mu \mathrm{m}$ were recorded with average and total values recorded.

Table 1 Experimental conditions used to measure induction times at different supersaturations in the MFOBC. Values show total numbers of experiments carried out with the number of different supersaturations in parentheses.

\begin{tabular}{|l|l|l|l|l|l|l|l|l|l|}
\hline \multirow{2}{*}{$\boldsymbol{f}(\mathbf{H z})$} & \multicolumn{9}{|c|}{$\boldsymbol{x}_{\mathbf{0}}(\mathbf{m m})$} \\
\cline { 2 - 11 } & $\mathbf{1}$ & $\mathbf{2}$ & $\mathbf{3}$ & $\mathbf{4}$ & $\mathbf{5}$ & $\mathbf{6}$ & $\mathbf{7}$ & $\mathbf{8}$ & $\mathbf{9}$ \\
\hline $\mathbf{1 . 0}$ & $3(3)$ & - & $10(4)$ & - & - & $14(5)$ & - & - & $14(5)$ \\
\hline $\mathbf{2 . 0}$ & - & $2(2)$ & $9(8)$ & $12(5)$ & - & $3(2)$ & - & - & - \\
\hline $\mathbf{3 . 0}$ & - & - & $5(5)$ & - & $13(5)$ & - & - & - & - \\
\hline $\mathbf{4 . 0}$ & $12(6)$ & $4(4)$ & $9(5)$ & - & - & - & - & $4(4)$ & - \\
\hline $\mathbf{5 . 0}$ & - & $9(6)$ & - & $4(3)$ & - & - & - & $3(3)$ & - \\
\hline $\mathbf{6 . 0}$ & $2(2)$ & - & - & $4(3)$ & - & - & - & - & - \\
\hline $\mathbf{7 . 0}$ & - & - & - & $4(4)$ & - & - & $4(3)$ & $3(3)$ & - \\
\hline $\mathbf{8 . 0}$ & - & - & - & $5(4)$ & $4(4)$ & - & - & $5(5)$ & - \\
\hline $\mathbf{9 . 0}$ & - & - & $2(2)$ & $2(2)$ & - & - & - & - & $3(3)$ \\
\hline
\end{tabular}

$f$ : frequency, $x_{0}$ : amplitude, - : no experiment performed.

The nucleation time values, corresponding with the first observation of crystals from the camera images, were measured. For FBRM nucleation was considered to have occurred at the first increase in the counts in the range $0.25-1000 \mu \mathrm{m}$. The induction time was determined as the time from the solution reaching constant temperature (supersaturation) to the measured initial nucleation time combined the methods of camera images and FBRM curves. After a nucleation event was measured, the solution was reheated to $15{ }^{\circ} \mathrm{C}$ above the solubility and held for 30 minutes until all particles had redissolved. The cooling and heating circulation were repeated multiple times varying the supersaturation and oscillatory conditions. Experiments were carried out in a randomised order.

In total 168 nucleation experiments were performed in the MFOBC, shown in Table 1. Fewer 
replicates at higher frequencies were carried out due to rupturing of the oscillating membrane after extended operation at these conditions. For the COFC experiments, $350 \mathrm{~mL}$ solutions were prepared and the experiments were performed in an identical manner to those used in the MFOBC experiments. Totally 45 induction time measurements were carried under the oscillatory and flow conditions shown in Table 2.

Table 2 Experimental conditions in MFOBC at frequency $2.0 \mathrm{~Hz}$ with amplitude $3 \mathrm{~mm}$ and in COFC at frequency $2.0 \mathrm{~Hz}$ with amplitude $3 \mathrm{~mm}$ or $5 \mathrm{~mm}$ with different net flow rates.

\begin{tabular}{llllllll}
\hline Exp. & & $f(\mathrm{~Hz})$ & $x_{0}(\mathrm{~mm})$ & $\mathrm{Q}(\mathrm{mL} / \mathrm{min})$ & $\mathrm{V}(\mathrm{mL})$ & Experiments & Sol. \\
\hline I & MFOBC & 2.0 & 3 & 0 & 120 & 18 & $1^{*}, 2$ \\
II & COFC & 2.0 & 3 & 60.0 & 280 & 16 & 3,4 \\
III & COFC & 2.0 & 5 & 0 & 280 & 16 & $4,5,6$ \\
IV & COFC & 2.0 & 5 & 100.0 & 280 & 13 & $4,7,8$ \\
\hline
\end{tabular}

$f$ : frequency, $x_{0}$ : amplitude, Q: pumping net flow rate, $\mathrm{V}$ : volume of solution, Concentration of Sol. (solution) 1-8: 2.490, 2.274, 2.050, 2.761, 2.541, 2.619, 2.569, $2.570 \mathrm{~g}$ butyl paraben / g ethanol, * same experiment of $2.0 \mathrm{~Hz}-3 \mathrm{~mm}$ in Table 1.

\section{Computation simulation procedure and boundary conditions}

All CFD models were three-dimensional in order to capture possible chaotic behaviour. The computational meshes were all hexahedral and structured. The computational cell size is less than $1 \mathrm{~mm}$ on average, with denser mesh close to the walls. The model equations were solved using the finite volume approach. First-order discretization schemes were used for the solution of the convection terms in all governing equations. The relative error between any two successive iterations was specified by using a convergence criterion of $1 \times 10^{-3}$ for all equations. The linearized equations for governing equations were solved using a block algebraic multigrid method. In order to ensure easy convergence of the various partial 
differential equations (PDE) in the model, the Courant-Friedrichs-Lewy (CFL) condition for three-dimensional PDE is followed:

$$
C=\frac{u_{x} \Delta t}{\Delta x}+\frac{u_{y} \Delta t}{\Delta y}+\frac{u_{z} \Delta t}{\Delta z} \leq C_{\max }
$$

where $C_{\max }$ is specified by the CFL condition to fall within the range of $\sim 1-5[32,33]$. In this study, a time step of 0.001 seconds was found to satisfy this condition. The liquid density $\rho 1000 \mathrm{~kg} \cdot \mathrm{m}^{-3}$ and dynamic viscosity $\mu_{l} 0.01613 \mathrm{~kg} \cdot \mathrm{m}^{-1} \mathrm{~s}^{-1}$, determined at $25^{\circ} \mathrm{C}$ with concentration of $2.5 \mathrm{~g}$ butyl paraben / g ethanol solution, was used in the simulation.

The OFC consist of a repeating series of cells as shown in Figure 2. The sinusoidal oscillatory movement is provided by a piston at one end of the reactor. The displacement, $\mathrm{z}_{\mathrm{p}}$ and the velocity, $\mathrm{u}_{\mathrm{z}}$, of the piston are given by

$$
\begin{aligned}
& z_{p}=-x_{0} \cos (2 \pi f t) \\
& u_{z}=2 \pi f x_{0} \sin (2 \pi f t)
\end{aligned}
$$

\section{Results}

Induction time in MFOBC as a function of oscillation

Figure 3 shows images of the butyl paraben solution inside the MFOBC (top row) and COFC (bottom row) and the evolution of their appearance from before (a) and after nucleation (b and c). The initial appearance of crystals with the subsequent increase in turbidity indicated the nucleation occurring. Following nucleation in both reactors a rapid increase in turbidity 
occurs due to secondary nucleation. Seeding experiments in a system of butyl paraben in ethanol show the solution becomes totally opaque in under 10 seconds after the addition of fine crystalline seeds particles under moderate shear rate. Compared with the length of induction (minutes or longer), the assumption is that influence of secondary nucleation has a limited influence on the induction time measurements in this work. In the COFC, the circulating solution through the pump is less than $5 \%$ of the volume of solution in the crystallizer, and the shear rate at the pump head speeds used is relatively low. Imaging does not show any evidence of primary nucleation in this section of the reactor. Therefore, the influence of the solution inside the recirculation section on the overall nucleation kinetics can be neglected. The FBRM data and more imaging data used to determine the induction times are provided as supporting information.

a)
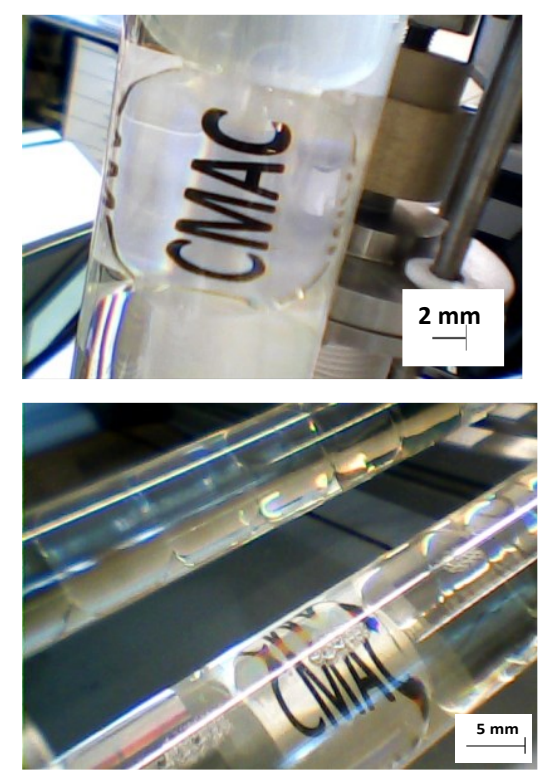

b)
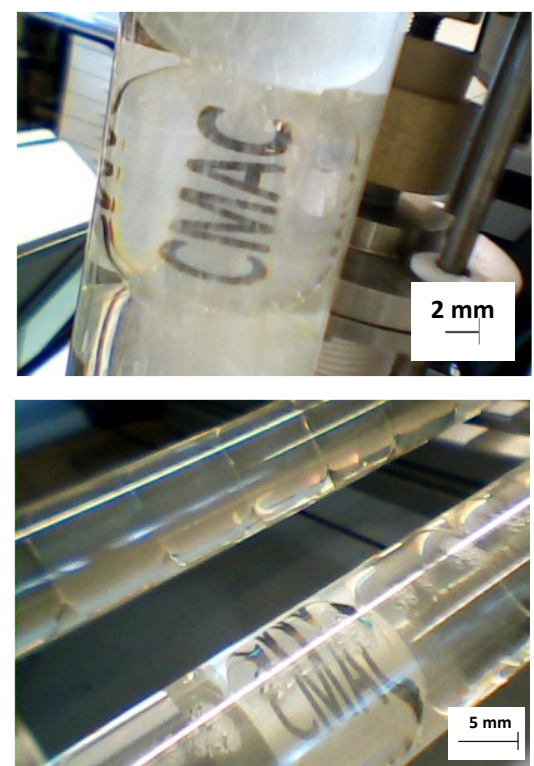

c)
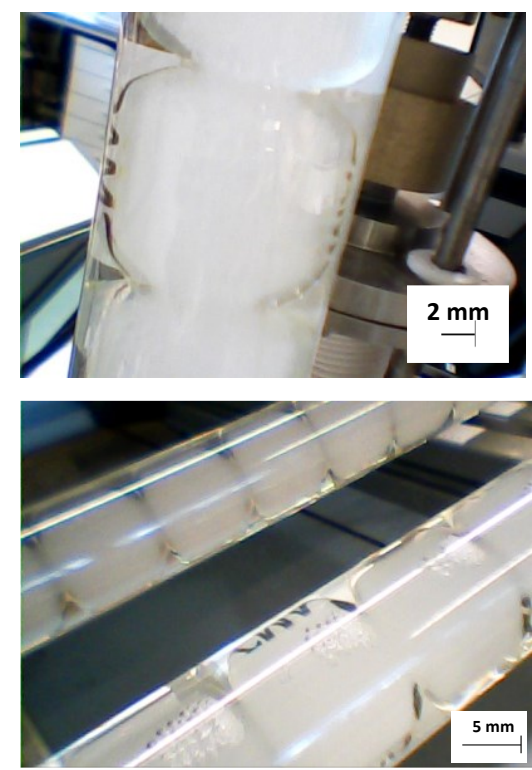

Figure 3 The progress of nucleation in the MFOBC (top row) and COFC (bottom row) after holding at a fixed supersaturation. Column a): both solutions prior to nucleation with the high contrast writing clearly visible through the solution. b): $<5$ seconds after the observed onset of nucleation with a significant increase in turbidity and partial obscuration of the 
writing. c): $<25$ seconds after nucleation with the rapid appearance of crystals to form a highly turbid suspension.

The natural logarithm of the induction times measured from each experiment at frequencies between 1.0 and $9.0 \mathrm{~Hz}$ are plotted vs $R T \mathrm{ln} S$ to show the range of nucleation times observed across the different frequencies and amplitudes investigated in this study (Figure 4). At equal oscillation conditions the induction time increases with decreasing driving force $(R T \ln S)$ as expected. Whilst most of the lines show similar gradients, some of the lines show an obvious deviation due to the limited number of experiments performed at those individual oscillatory conditions. There is an obvious effect on the induction time at equal driving force from both frequency and amplitude. At each frequency tested from 1.0 $\mathrm{Hz}$ to $6.0 \mathrm{~Hz}$ (top two rows in Figure 4) the induction times at comparable values of RTInS tend to decrease with increasing amplitude. At the lowest frequency, $1.0 \mathrm{~Hz}$, the reduction in induction time as amplitude increases from 1 to $9 \mathrm{~mm}$ is greater than that observed at any other frequency. Notably, above $7.0 \mathrm{~Hz}$ the induction times tends to increase with increasing amplitude for comparable $R T \ln S$ values (bottom row in Figure 4). 


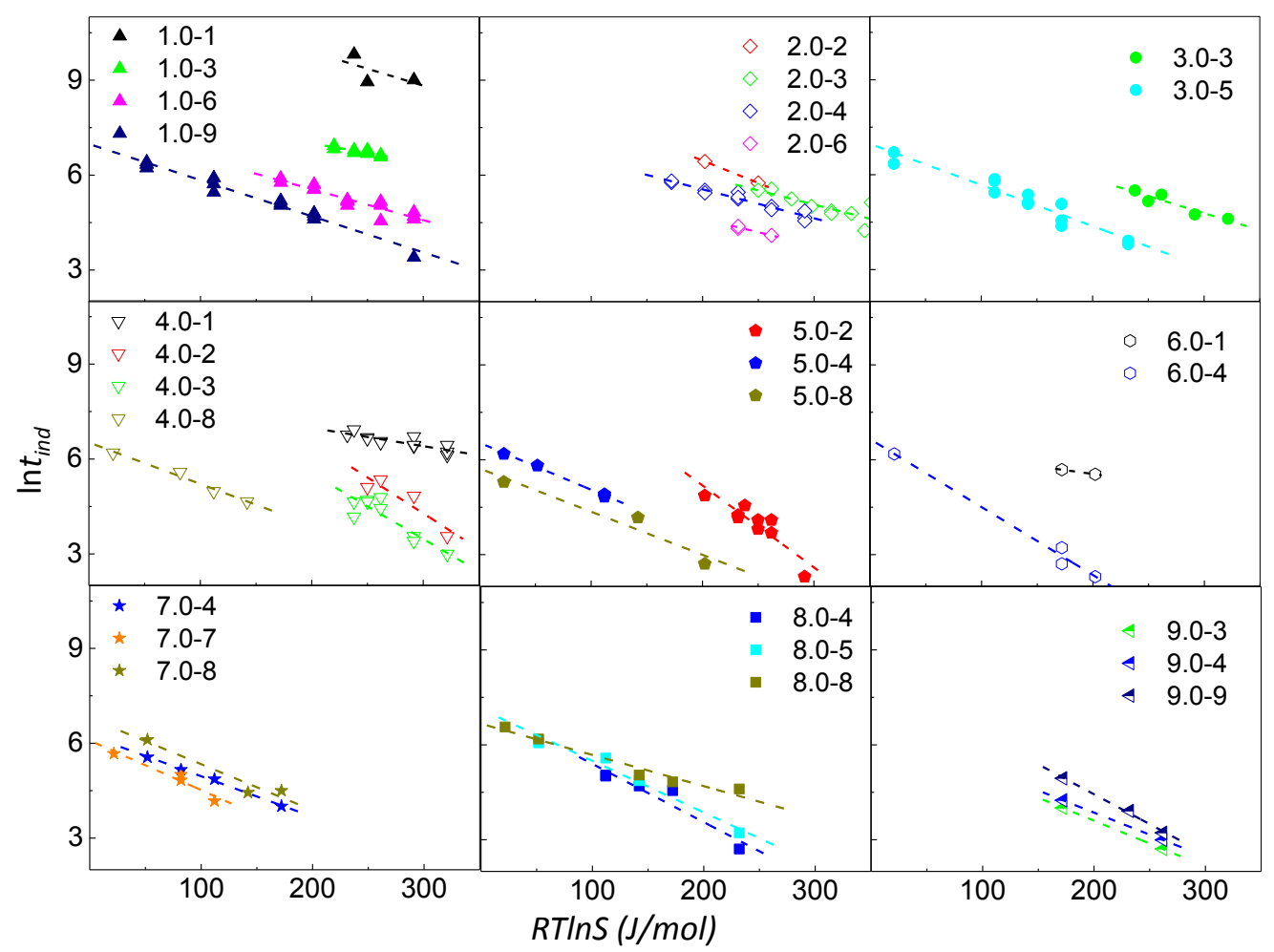

Figure 4 Induction time (Int $\left.t_{\text {ind }}\right)$ vs. driving force $(R T \ln S)$ of nucleation in the MFOBC under different amplitudes with each frequency, respectively. Legend: Frequency $(\mathrm{Hz})$ - amplitude $(\mathrm{mm})$. Dashed lines are fitted lines for the linear correlation of the respective experimental data.

Induction times under different frequencies for each value of amplitude tested are shown in the supporting information. At each oscillatory amplitude from $1 \mathrm{~mm}$ to $6 \mathrm{~mm}$ the induction times tend to decrease with increase of the frequency under comparable $R T \ln S$ values, and at the lowest amplitude, $1 \mathrm{~mm}$, the decreased induction time with increase of the frequency is higher than at other amplitudes. However, at $8 \mathrm{~mm}$ the induction times tend to increase with increasing frequency from $5.0 \mathrm{~Hz}$ to $8.0 \mathrm{~Hz}$ under comparable equal driving force. A plot of all induction time results vs. $R T \ln S$ (shown in the supporting information) shows a much stronger influence of oscillation conditions at lower amplitudes and frequencies than in the high region, which is consistent with Figure 4. This tendency is in agreement with the 
simulation results [34] that nucleation behaviour is more sensitive to the shear rate at lower shear rate regime than at higher shear rate regime.

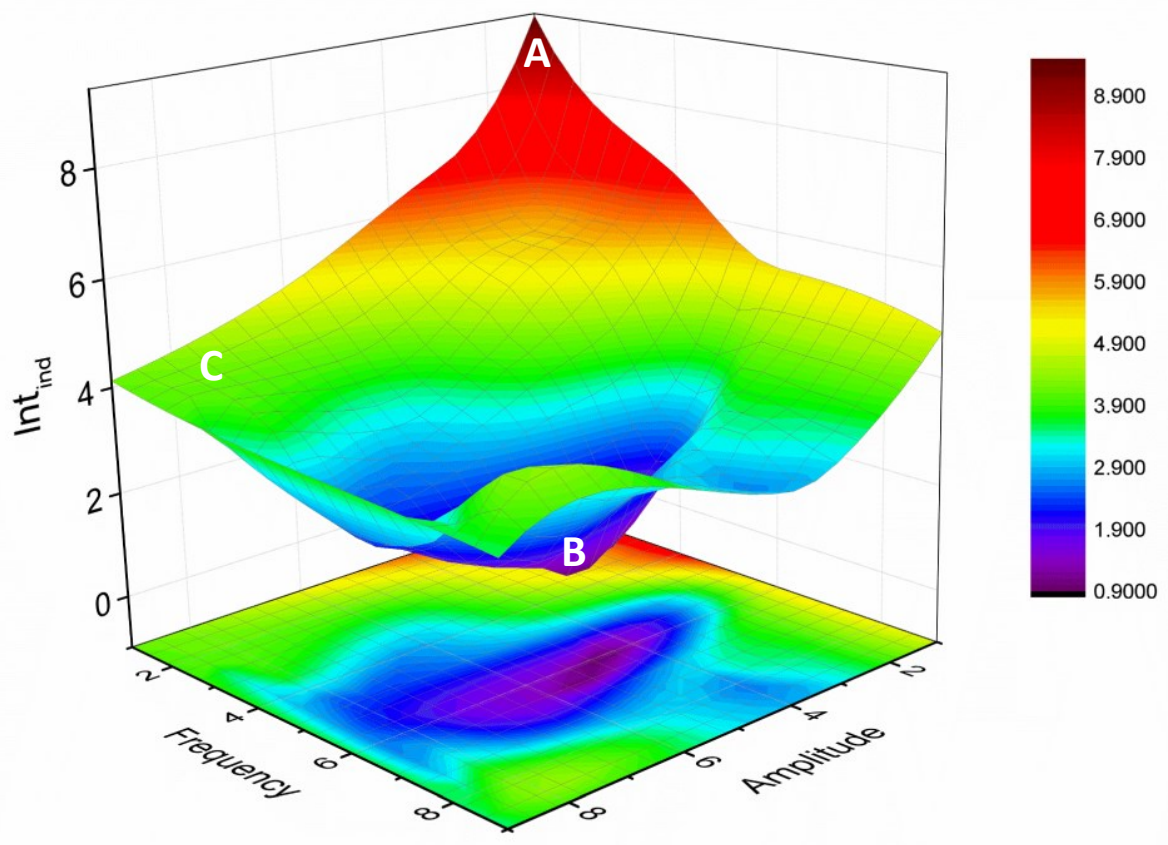

Figure 5 Estimated induction time at driving force $(R T \ln S) 200 \mathrm{~J} / \mathrm{mol}$ of butyl paraben in ethanol with various frequencies and amplitudes in the MFOBC.

The induction times at $R T \ln S 200 \mathrm{~J} / \mathrm{mol}$ were estimated from the linear correlation lines in Figure 4 at each set of oscillatory conditions, and the relation between the extrapolated induction time with amplitude and frequency is shown as a response surface in Figure 5 . The longest induction time (region A, red, Figure 5) is almost three orders of magnitude greater than the shortest induction time. Increasing the frequency and amplitude above $1.0 \mathrm{~Hz} / 1$ $\mathrm{mm}$ shows a significant decrease in the induction time in region A. Similar values of induction time are found across a range of oscillatory conditions (region C, green, Figure 5). The minimum values for induction time of all conditions are shown between $5-7 \mathrm{~Hz}$ and 5-7 $\mathrm{mm}$ (point $\mathrm{B}$, purple, Figure 5). A similar tendency of the nucleation behaviour was also 
reported for butyl paraben in ethanol solution in a stirred glass vessel between $100-800$ rpm, which displayed a minimum induction time for stirring rates around $200 \mathrm{rpm}$ [35].

The power density, $\frac{P}{V}$, Reynolds number, $R_{e_{0}}$ and Strouhal number $S_{t}$ of an oscillation crystallizer are calculated [10] as:

$$
\begin{gathered}
\frac{P}{V}=\frac{2 \rho_{l} N_{b}}{3 \pi C_{D}^{2}}\left(\frac{A_{1}^{2}-A_{2}^{2}}{A_{2}^{2}}\right)\left(2 \pi f x_{0}\right)^{3} \\
R_{e_{0}}=\frac{2 \pi f x_{0} \rho_{l} D}{\mu_{l}}\left(\frac{A_{1}^{2}-A_{2}^{2}}{A_{2}^{2}}\right)\left(2 \pi f x_{0}\right)^{3} \\
S_{t}=\frac{D}{4 \pi x_{0}}
\end{gathered}
$$

where $N_{b}$ is the number of baffles per unit length, $\mathrm{C}_{\mathrm{D}}$ is the coefficient of discharge of the baffles ( 0.7), $A_{1}$ and $A_{2}$ is cross sectional area of the tube and of the baffle orifice, respectively. $D$ is the internal diameter of the crystallizer. From equations (15), (16) and (17), power density, $R_{e_{0}}$ and $S_{t}$ can be estimated in the range of frequency $1 \mathrm{~Hz} \leq f \leq 9 \mathrm{~Hz}$ and amplitude $1 \mathrm{~mm} \leq x_{0} \leq 9 \mathrm{~mm}$. Figure 6 shows that induction time decreases with increasing power density and $t_{\text {ind }} \propto\left(\frac{\mathrm{P}}{\mathrm{V}}\right)^{-0.59}$ when power density is below $500 \mathrm{~W} / \mathrm{m}^{3}$ $\left(R_{e_{0}} \sim 200\right)$. A similar relationship has been reported for the nucleation kinetics of butyl paraben in ethanol solution in small stirred glass vessels [35]. As power density is increased above $1000 \mathrm{~W} / \mathrm{m}^{3}\left(R_{e_{0}} \sim 300\right)$, the induction time starts to increase. It has been reported that at $R_{e_{0}}$ values above 300 a more turbulent, well mixed flow scheme develops within oscillatory baffled reactors [36]. In this high shear range, the induction time shows a positive correlation with power density with $t_{\text {ind }} \propto\left(\frac{\mathrm{P}}{\mathrm{V}}\right)^{0.46}$ (Figure 6). 


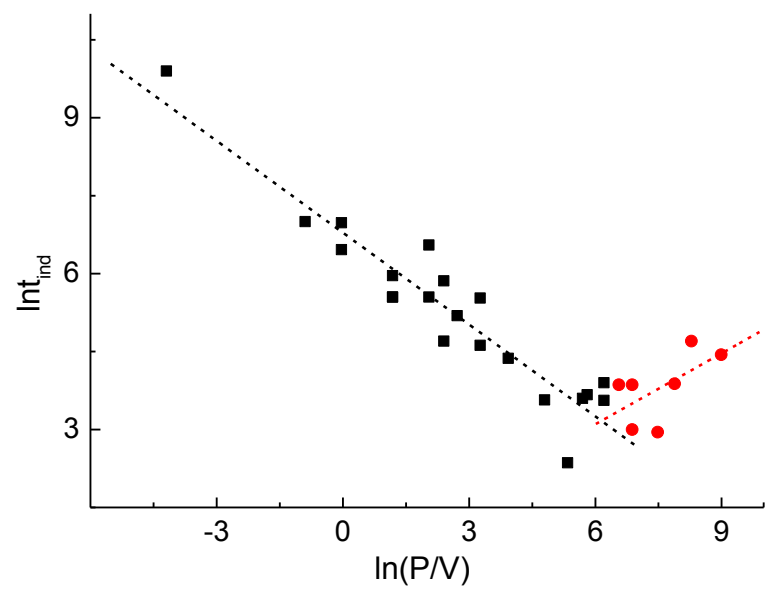

Figure 6 Estimated induction time at $R T \ln S=200 \mathrm{~J} / \mathrm{mol}$ versus power density in the MFOBC. Dashed lines show best fit to the respective data, black $<\ln (P / V)=6.2<$ red.

Strouhal number is the ratio of column diameter to stroke length, and in this work, the Strouhal numbers are in the range 1.3 to 0.2 indicating a collective oscillating movement of the fluid "plug" [37] regardless of the size of the Reynolds number. For the experimental conditions with equivalent power densities, the induction time tends to decrease with increasing amplitude (shown in supporting information), i.e. decreasing Strouhal number. Exceptions to this trend are $6.0 \mathrm{~Hz}-1 \mathrm{~mm}, 4.0 \mathrm{~Hz}-8 \mathrm{~mm}$ and $8.0 \mathrm{~Hz}-4 \mathrm{~mm}$. Further data under these conditions would be required to assess the statistical significance of these particular results.

\section{Simulated hydrodynamics in MFOBC and COFC}

A LES model based CFD simulation was implemented to simulate the hydrodynamics of the liquid phase in the COFC geometry (horizontal arrangement) at a range of flow rates, $Q=0$, 60 and $100 \mathrm{~mL} / \mathrm{min}$. $0 \mathrm{~mL} / \mathrm{min}$ is equivalent to the conditions within a batch operated MFOBC (i.e. frequency and amplitude with no net flow) whilst the values of $Q>0$ are 
equivalent to a continuously operated COFC. The simulated results showed the reactor cell has periodic symmetry of the flow pattern after just few seconds of fluctuation, and accordingly 3 cells are used to represent 15 cells in the experimental setup (Figure 7). The simulation results indicate that the flow within each oscillatory baffled crystallizer is subject to both temporal and spatial periodicity. The spatial periodicity is shown in Figure 7a and Figure 7c, which are snapshots of the velocity and shear rate spatial distribution, respectively. The velocity and shear rates increase or decrease along the radial direction. The temporal periodicities are shown in Figure $7 \mathrm{~b}$ and Figure $7 \mathrm{~d}$ and highlight the evolution of axial velocity and shear rate at point $d$ (in the high shear rate region), respectively. Figure 7 shows an example of the simulation results at $0.5 \mathrm{n} s$ ( $\mathrm{n}$ is an integral number) when the piston velocity is zero and located at the negative maximum distance (amplitude distance, $\mathrm{mm}$ ). Due to the periodic movement of the piston, the flow of liquid is accelerated as it passes the baffles. Therefore, a maximum axial velocity appears around the baffle connecting two neighbouring cells. The shear rate is directly related to the gradient or derivative of velocity, and the maximum shear rate appears where the deformation of liquid is large, particularly near the baffles. The simulated eddies appear before and after the solution passes through the baffle orifice, indicating intensive turbulence in this region, which is consistent with the experimental observation. The influence on the shear rate and velocity distributions of moving from a horizontal to a vertical orientation were also calculated under identical oscillation conditions. The simulation results show the influence of gravity is negligible. 

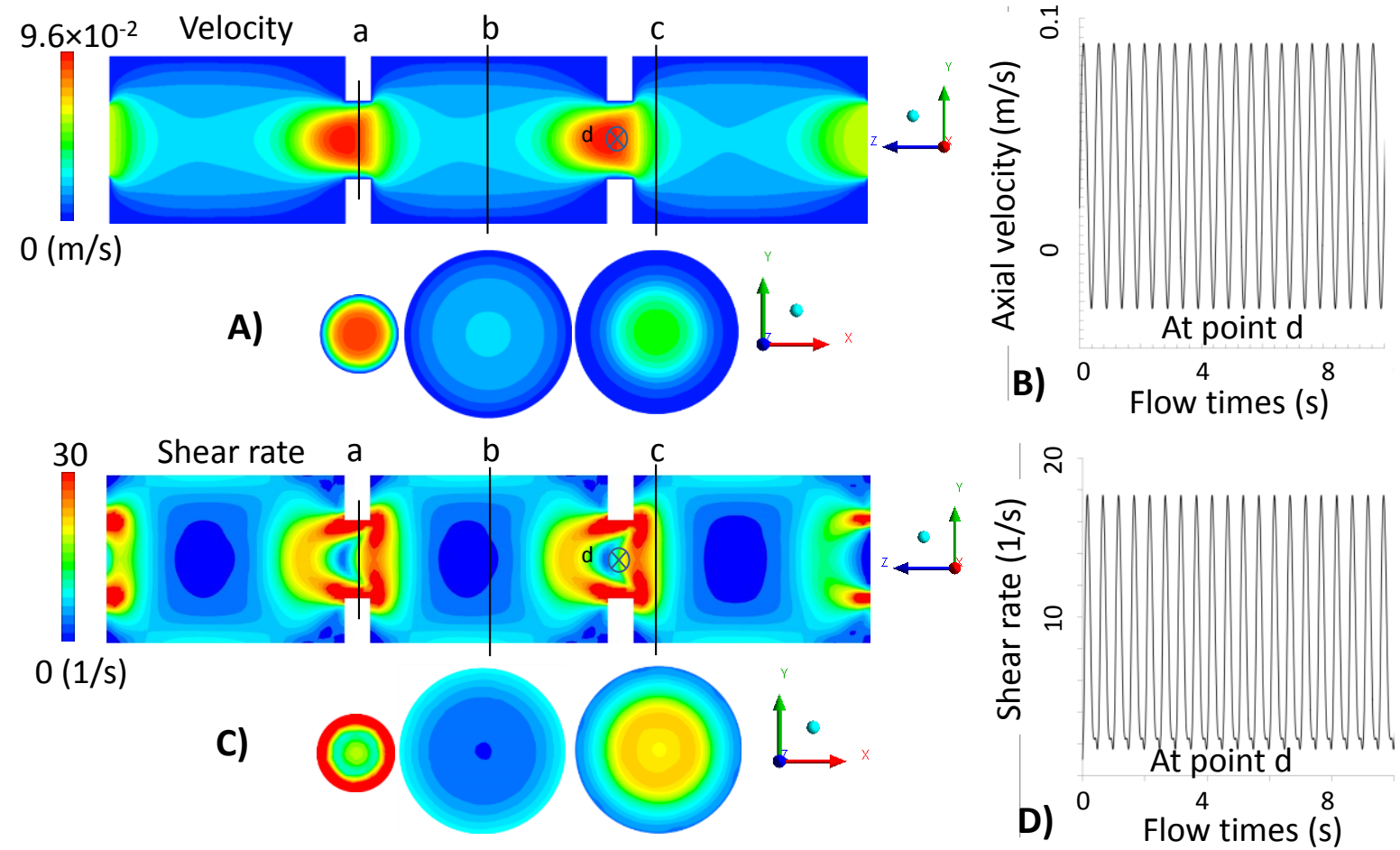

Figure 7 The 3D CFD simulated hydrodynamic behaviours for a liquid phase at $2.0 \mathrm{~Hz}-3 \mathrm{~mm}$ $60 \mathrm{ml} / \mathrm{min}$. A. velocity vector at $0.5 \mathrm{n} \mathrm{s}, \mathrm{B}$. temporal axial velocity at monitor point $\mathrm{d}$ in the centre of the baffle orifice, $C$. shear rate vector at point $d$ at $0.5 n s$ and $D$. temporal shear rate at point $d$.

Simulations I, II, III and IV were at the same oscillation conditions as Experiment I, II, III and IV (Table 2), respectively, but with horizontal COFC employed in all the simulations. Net flow causes an increase in the velocity curve at point d (Figure 7) at both $2.0 \mathrm{~Hz}-3 \mathrm{~mm}$ and 2.0 $\mathrm{Hz}-5 \mathrm{~mm}$ cases (Figure 8). Without net flow applied the velocity at point $\mathrm{d}$ is positive for $50 \%$ of the oscillatory period of the piston movement and rises to $75 \%$ of the period of the piston oscillation with a net flow applied. When the piston movement is aligned with the direction of net flow the solution velocity is enhanced, and accordingly shear rate increases. When the piston movement is in the opposite direction to the net flow the velocity is reduced. 


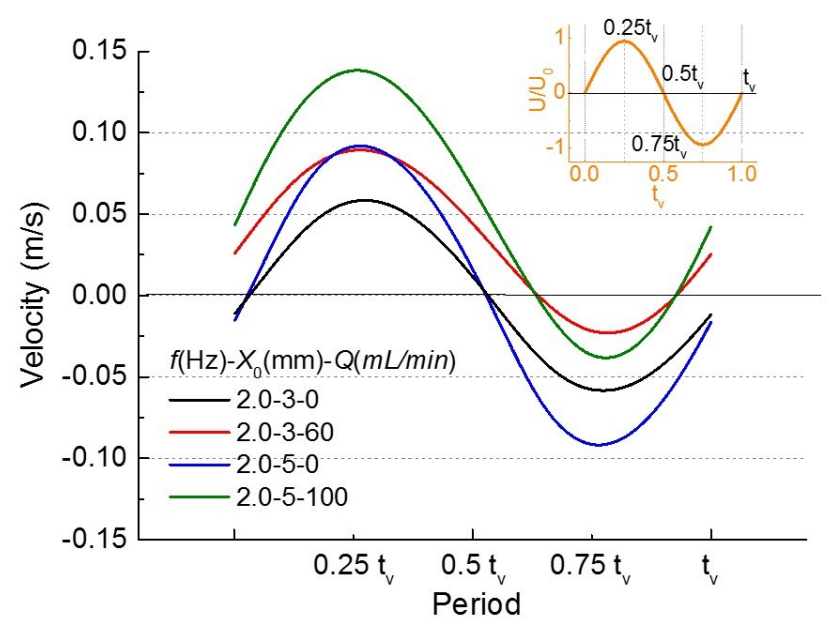

Figure 8 Simulated velocity of flow at point $d$ in same period of piston velocity

The accumulated spatial distributions of the shear rate at each time point $0.25 t_{V}, 0.5 t_{V}$, $0.75 t_{V}$ and $t_{V}$ within a period of the piston velocity are shown in Figure 9 . The overall shear rate at each time point is generally higher at $5 \mathrm{~mm}$ amplitude than at $3 \mathrm{~mm}$. This indicates a stronger influence of a $2 \mathrm{~mm}$ increase in oscillation amplitude compared with a $60 \mathrm{~mL} / \mathrm{min}$ increase of net flow on these two distributions. However at $0.5 t_{V}$ the shear rate distribution at $3 \mathrm{~mm}$ amplitude and $60 \mathrm{~mL} / \mathrm{min}$ net flow is very slightly higher than at $5 \mathrm{~mm}$ amplitude and $0 \mathrm{~mL} / \mathrm{min}$. From the shear rate distribution, the shear rate with the largest volume fraction from simulation I is $1.3 \mathrm{~s}^{-1}$ at $0.5 t_{V}$ with a volume fraction about $19.5 \%$, for simulation II it is $1.3 \mathrm{~s}^{-1}$ at $t_{V}$ with volume fraction about $13.3 \%$, simulation III is 12.5 $s^{-1}$ at $t_{V}$ with a volume fraction of $14.9 \%$, and in simulation IV the value is $12.5 \mathrm{~s}^{-1}$ at $t_{V}$ with a volume fraction about $24.8 \%$. For simulations I, II, III and IV, the median value of the shear rate distribution is in the range of $1.8-4.3 s^{-1}, 2.5-5.5 s^{-1}, 3.5-7.0 s^{-1}$, and $4.5-$ $11.2 s^{-1}$ respectively. The maximum shear rate for the highest $10 \%$ volume fraction is in the range $12.8-52.5 s^{-1}, 17.5-87.5 s^{-1}, 22.5-97.5 s^{-1}$ and $32.5-150.0 s^{-1}$. They are all in order simulation I $<$ II $<$ III $<$ IV. The increase in standard deviation of shear rate at the four 
time point $0.25 t_{V}, 0.5 t_{V}, 0.75 t_{V}$ and $t_{V}$ follows the same order, indicating a larger fluctuation of spatial and temporal shear rate with increasing shear rate (higher amplitude or higher net flow; Table 4).

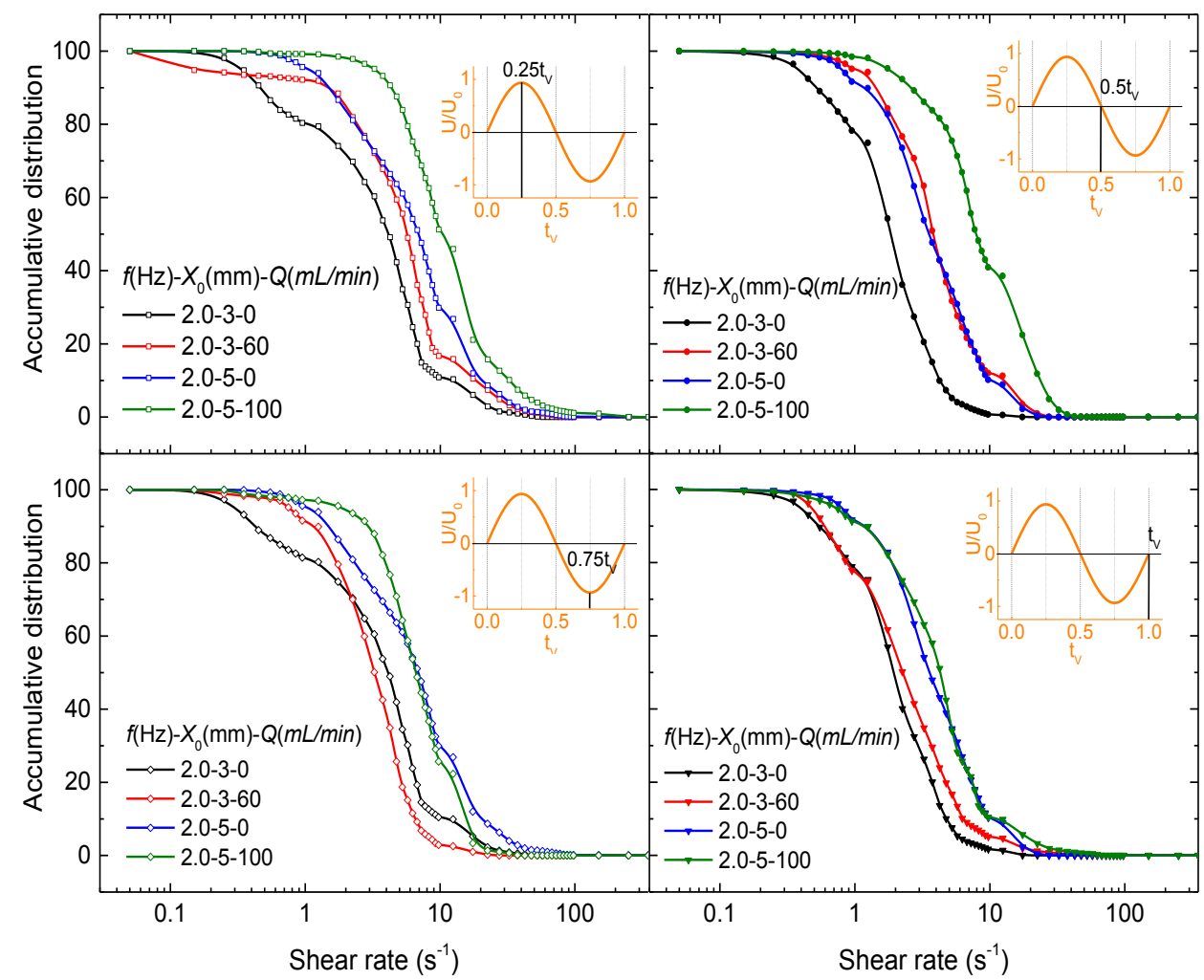

Figure 9 Accumulated volume distributions of the shear rate at different time points of the oscillatory flow, specifically $0.25 t_{V}, 0.5 t_{V}, 0.75 t_{V}$ and $t_{V}$ of a period of piston velocity. Each curve shows the accumulated volume distribution for different operation conditions denoted as [frequency - amplitude - net flow rate]: (black) $2.0 \mathrm{~Hz}-3 \mathrm{~mm}-0 \mathrm{~mL} / \mathrm{min}$ (red) $2.0 \mathrm{~Hz}-3 \mathrm{~mm}-60 \mathrm{ml} / \mathrm{min}$ (blue) $2.0 \mathrm{~Hz}-5 \mathrm{~mm}-0 \mathrm{ml} / \mathrm{min}$ (green) $2.0 \mathrm{~Hz}-5 \mathrm{~mm}-100$ $\mathrm{ml} / \mathrm{min}$

At $0 \mathrm{~mL} / \mathrm{min}$ the accumulated spatial shear rate distributions are almost overlapping at 0.25 $t_{V}$ and $0.75 t_{V}$ (supporting information), where the piston velocity is at a maximum, and are almost overlapping at $0.5 t_{V}$ and $t_{V}$, where the velocity of the piston at the inlet is zero. When net flow is applied, the shear rate distributions become more complicated. 
Comparing simulations II and III, a similar tendency is captured: a) the shear rate at $0.25 t_{V}$ is higher than $0.5 t_{V}$ which are both higher than the shear rate at other time points, $\mathrm{b}$ ) the shear rate at $t_{V}$ is higher than $0.75 t_{V}$ in the high shear region (above $15 \mathrm{~s}^{-1}$ ) and the shear rate at $t_{V}$ is lower than $0.75 t_{V}$ in the lower shear region (supporting information). This is consistent with the average shear rates shown in Table 3. In simulations I and III the highest and lowest average shear rate alternately appears every $0.25 t_{V}$. Whereas in simulations II and IV the highest average shear rate and the lowest average shear appears at $0.25 t_{V}$ and $t_{V}$, respectively. The difference of shear rate among simulation I - IV is smallest at time point $t_{V}$, which is highest at time point $0.25 t_{V}$ shown in Table 3.

Table 3 Average and max shear rate in simulation I, II, III and IV with standard deviations

\begin{tabular}{|c|l|r|r|r|r|r|c|}
\hline \multirow{2}{*}{$\begin{array}{l}\text { Sim } \\
\text { ulat } \\
\text { ion }\end{array}$} & $\begin{array}{l}\text { Conditions } \\
\mathrm{f}(\mathrm{Hz})-\mathrm{XO}(\mathrm{mm})-\end{array}$ & \multicolumn{3}{|c|}{ Average shear rate $\left(\mathrm{s}^{-1}\right)$ at time } & & $\begin{array}{c}\text { 10\% maximum } \\
\text { point }\end{array}$ \\
\cline { 2 - 8 } & $\mathrm{Q}(\mathrm{mL} / \mathrm{min})$ & $\begin{array}{c}0.25 \\
t_{V}\end{array}$ & $0.5 t_{V}$ & $\begin{array}{c}0.75 \\
t_{V}\end{array}$ & $t_{V}$ & $\begin{array}{c}\text { Standard deviation rate of } \\
\text { for each simulation }\end{array}$ & $\begin{array}{c}\text { the volume } \\
\text { distribution }\left(\mathrm{s}^{-1}\right)\end{array}$ \\
\hline I & $2.0-3-0$ & $\mathbf{5 . 1 1}$ & $\mathbf{2 . 3 4}$ & $\mathbf{5 . 1 1}$ & $\mathbf{2 . 3 4}$ & $\mathbf{1 . 3 9}$ & $12.75-52.50$ \\
\hline II & $2.0-3-60$ & $\mathbf{7 . 5 4}$ & 4.87 & 3.55 & $\mathbf{3 . 2 1}$ & 1.70 & $17.50-87.50$ \\
\hline III & $2.0-5-0$ & $\mathbf{8 . 9 8}$ & $\mathbf{4 . 6 2}$ & $\mathbf{8 . 9 8}$ & $\mathbf{4 . 6 2}$ & 2.12 & $22.50-97.50$ \\
\hline IV & $2.0-5-100$ & $\mathbf{1 4 . 6 0}$ & 10.25 & 7.33 & $\mathbf{5 . 4 6}$ & $\mathbf{3 . 4 5}$ & $32.50-150.00$ \\
\hline & $\begin{array}{l}\text { Standard deviation } \\
\text { at each time point }\end{array}$ & $\mathbf{3 . 4 9}$ & 2.90 & 2.07 & $\mathbf{1 . 2 1}$ & & \\
\hline
\end{tabular}

\section{Nucleation parameters in MFOBC and COFC}

Figure 10 shows the experimental results, induction times, Int $t_{\text {ind, }}$ of solutions $1-8$ with different concentrations in the MFOBC and COFC platforms (Table 2) versus $T^{-3} \ln S^{-2}$. The linear regression solid and dashed lines in Figure 10 for determining the interfacial energy and pre-exponential factor in the homogeneous nucleation and in the heterogeneous nucleation are nearly parallel to each other, respectively. In Figure 10, the induction time 
decreased (Exp. I > Exp. II > Exp. III > Exp. IV) under comparable supersaturation in both homogeneous nucleation and heterogeneous nucleation due to the influence of the oscillatory conditions and the net flow rates by changing the shearing condition, as well as the influence of the solution volume which is consistent with that metastable zone widths decrease with increasing of solution volumes $[34,38,39]$. Because of the stochastic nature of the nucleation processing, the average values of $R^{2}$ for all the linear correlation are about 0.83 , where the $R^{2}$ values are overall lower in the heterogeneous nucleation (dashed lines) than in the homogeneous nucleation (solid lines).

In the homogeneous nucleation region, the solid-liquid interfacial energies, $\sigma_{\mathrm{HON}}$, of butyl paraben - ethanol in the MFOBC at $2.0 \mathrm{~Hz}-3 \mathrm{~mm}$ is $1.137 \mathrm{~mJ} \cdot \mathrm{m}^{-2}$, determined by Equ. (2), and in the COFC the interfacial energies are $1.134,1.094$ and $1.051 \mathrm{~mJ} \cdot \mathrm{m}^{-2}$ for $2.0 \mathrm{~Hz}-3$ $\mathrm{mm}$ at $60 \mathrm{~mL} / \mathrm{min}$ and $2.0 \mathrm{~Hz}-5 \mathrm{~mm}$ at $0 \mathrm{~mL} / \mathrm{min}$ and $100 \mathrm{~mL} / \mathrm{min}$, respectively. The interfacial energies in the homogeneous nucleation in these experiments are in good agreement, with a standard deviation of only $0.0350 \mathrm{~mJ} \cdot \mathrm{m}^{-2}$, and the values are also consistent with the values, $1.14-1.16 \mathrm{~mJ} \cdot \mathrm{m}^{-2}$, measured in other platforms $[23,35]$. The interfacial energy, $\sigma_{\mathrm{HEN}}$, in the heterogeneous nucleation are determined by Equ. (4) shown in Table 4, which are in the range of about $0.50 \mathrm{~mJ} \cdot \mathrm{m}^{-2}$ to $0.55 \mathrm{~mJ} \cdot \mathrm{m}^{-2}$ with the activity coefficient factor about $0.46-0.50$, and the standard deviations also indicate the consistence between the interfacial energies in the heterogeneous nucleation in these experiments. From inspection of the intersections of the fitted lines in Figure 10, at higher shear rates the nucleation mechanisms tends to shift to a heterogeneous regime at a slightly lower driving force, and this tendency is also in agreement with butyl paraben in ethanol as 
a function of increasing stirring rate [35]. These indicate under higher shear rate heterogeneous nucleation become a little more unfavourable.

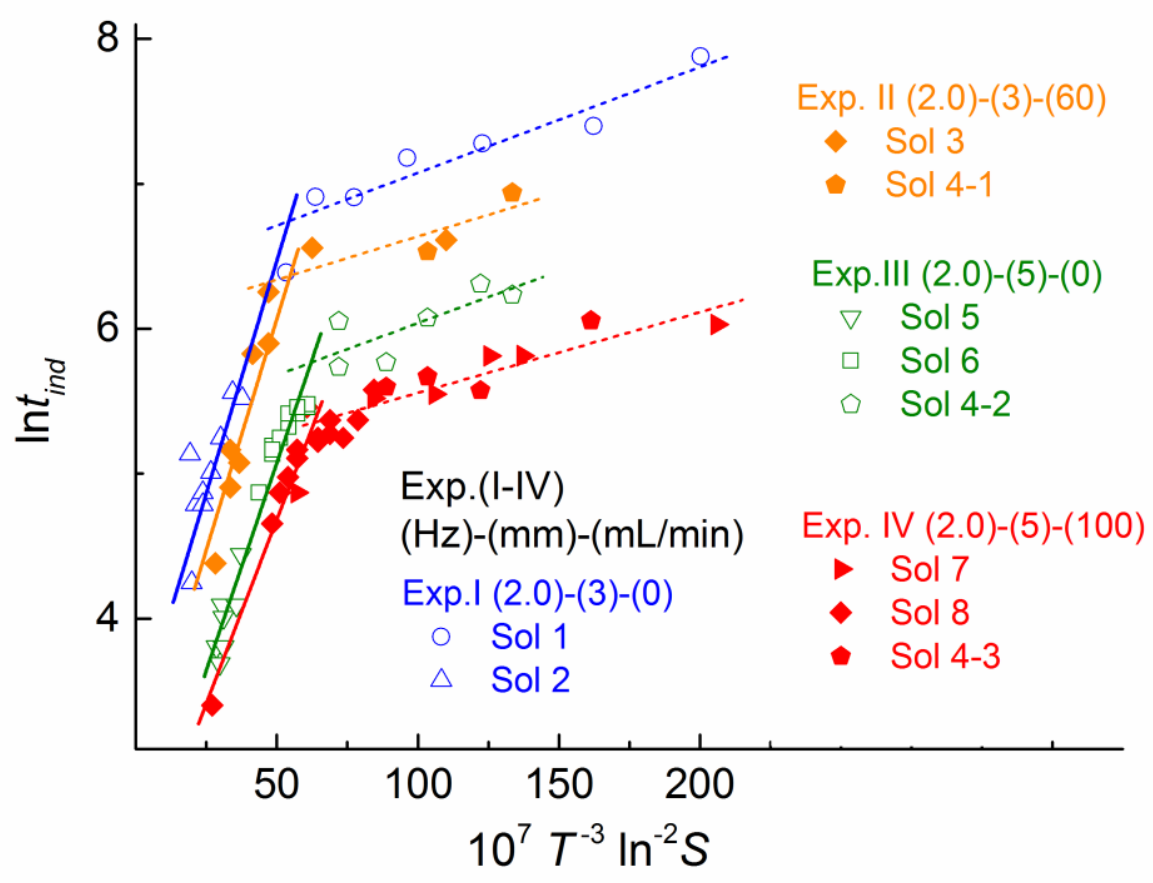

Figure $10 \ln$ induction time $\left(\ln t_{\text {ind }}\right)$ vs. $T^{-3}(\ln S)^{-2}$ in the MFOBC and COFC. Dashed and solid lines are best fitting linear lines for the respective data. 
Table 4 Interfacial energy and pre-exponential factor of butyl paraben-ethanol in homogeneous and heterogeneous nucleation

\begin{tabular}{|c|c|c|c|c|c|c|c|}
\hline Exp. & $\begin{array}{c}\sigma_{H O N} \\
(\mathrm{~mJ} \cdot \\
\left.\mathrm{m}^{-2}\right)\end{array}$ & $\begin{array}{c}A_{H O N} V \\
\left(\mathrm{~s}^{-1}\right)\end{array}$ & $\begin{array}{c}\sigma_{H E N} \\
(\mathrm{~mJ} \cdot \\
\left.\mathrm{m}^{-2}\right)\end{array}$ & $\begin{array}{c}A_{H E N} V \\
\left(\mathrm{~s}^{-1}\right)\end{array}$ & $\gamma$ & $\begin{array}{c}|\overline{\mathrm{r}}| \\
\left(\mathrm{s}^{-1}\right)\end{array}$ & $\begin{array}{c}\overline{|u|} \\
\left(\mathrm{m} \cdot \mathrm{s}^{-1}\right)\end{array}$ \\
\hline $\mathrm{I}$ & 1.137 & 0.038 & 0.551 & 0.0017 & 0.48 & 3.73 & 0.037 \\
\hline $\mathrm{II}$ & 1.134 & 0.056 & 0.515 & 0.0024 & 0.46 & 4.79 & 0.043 \\
\hline III & 1.094 & 0.110 & 0.548 & 0.0049 & 0.50 & 6.80 & 0.059 \\
\hline IV & 1.051 & 0.116 & 0.503 & 0.0067 & 0.48 & 9.41 & 0.068 \\
\hline $\begin{array}{l}\text { Standard } \\
\text { deviation }\end{array}$ & 0.035 & & 0.021 & & 0.02 & & \\
\hline
\end{tabular}

$\gamma=\sigma_{\mathrm{HEN}} / \sigma_{\mathrm{HON}},|\overline{\mathrm{r}}|$ : average shear rate at four time points $\left(0.25 \mathrm{t}_{\mathrm{V}}, 0.5 \mathrm{t}_{\mathrm{V}}, 0.75 \mathrm{t}_{\mathrm{V}}\right.$ and $\left.\mathrm{t}_{\mathrm{V}}\right)$ at each experiment. $\overline{|u|}$ : average absolute velocity during a period of piston velocity

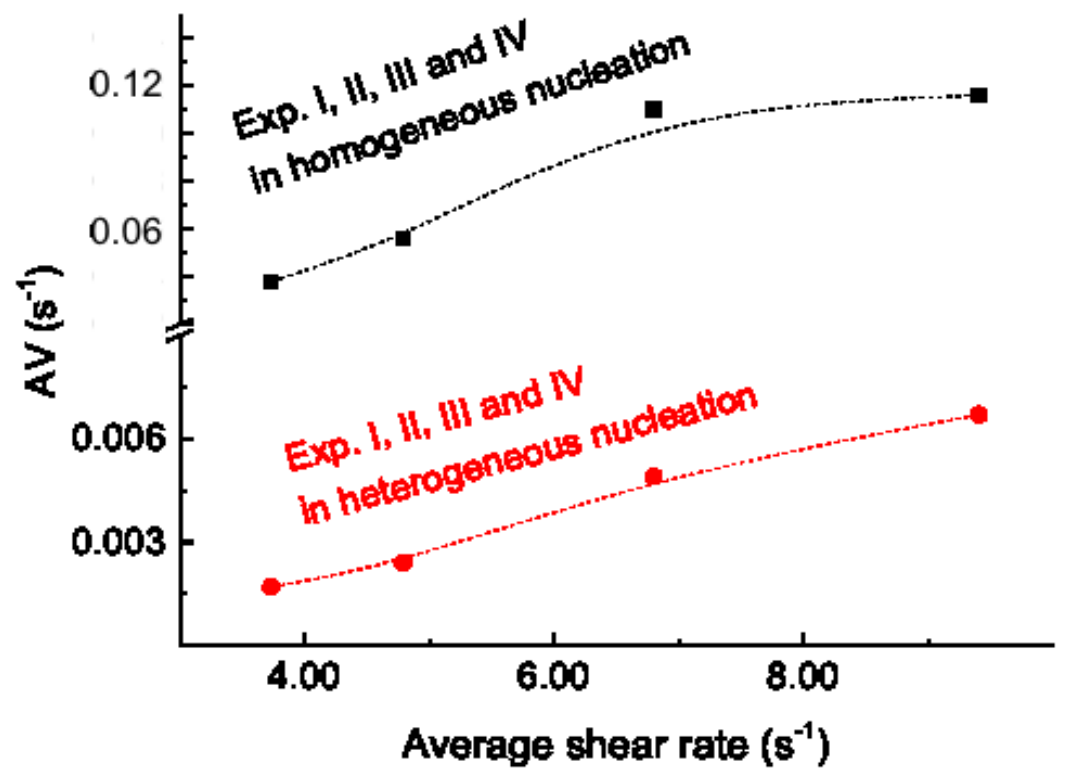

Figure 11 Relation between pre-exponential factors with average shear rates with guiding dashed lines. Experiment I to IV (Table 2) from left to right.

The calculated pre-exponential factors for homogeneous nucleation of butyl paraben are relatively low, which have similar orders of magnitude as those reported in previous experiments [34]. The pre-exponential factor, $A V$, in both the homogeneous and heterogeneous nucleation regimes increases in the order Exp. I $<$ Exp. II < Exp. III < Exp. IV 
with $A_{H E N} V$ nearly one or two orders of magnitude lower than the value of $A_{H O N} V$ across all conditions. This may be due to the lower number of potential nucleation sites available in heterogeneous nucleation (foreign particles) compared with homogeneous nucleation (molecules/molecular clusters) [29]. The pre-exponential factors, $A V$, increase with averaged shear rates (from the CFD simulation results) in homogeneous and heterogeneous nucleation, respectively (Figure 11). This is due to enhancing the attachment frequency and probably decreasing the energy barrier for diffusion or desolvation. The shear rate has a stronger influence on the pre-exponential factors in heterogeneous nucleation $\left(A_{H E N} V\right.$ in Exp. IV is about 4 times than in Exp. I) than in homogeneous nucleation $\left(A_{H O N} V\right.$ in Exp. IV is about 3 times than in Exp. I).

\section{Discussion}

The interfacial energy values in homogeneous nucleation determined in this work are consistent with each other as well as with values from other studies [23,35]. As expected, the critical radius of the cluster decreases with increasing driving force / supersaturation at each of the four mixing conditions tested. The variation in critical nucleus size under different mixing conditions also tends to reduce with increased supersaturation. This may be as a result of reduced sensitivity of smaller critical nuclei to changes in average shear under experimental conditions in Exp. I - IV, compared with larger clusters comprising more molecules obtained at lower supersaturations. The same tendency has been observed in butyl paraben - ethanol solution in a Taylor-Couette flow system [35]. 
The influence of shear rate on metastable zone width and induction time over limited ranges [41, 42] can be explained in several ways including enhanced mass transfer of molecules to the cluster, inducing molecular ordering [43] or by promoting secondary nucleation following an initial primary nucleation event [42] [44]. The results from this work (Figures 5 and 6) and from other systems including L-glutamic Acid [45], $\mathrm{HN}_{3} \mathrm{H}_{2} \mathrm{PO}_{4}, \mathrm{MgSO}_{4}$, $\mathrm{NaNO}_{4}[46,47]$ and $\mathrm{H}_{2} \mathrm{O}[48]$ emphasise that the interaction between nucleation rate and shear rates over extended ranges can vary quite significantly. This is perhaps to be expected in light of the dependency of cluster growth, coalescence and breakup that can combine to lead to an increase or decrease in nucleation rate as shear rate increases [47], [48].

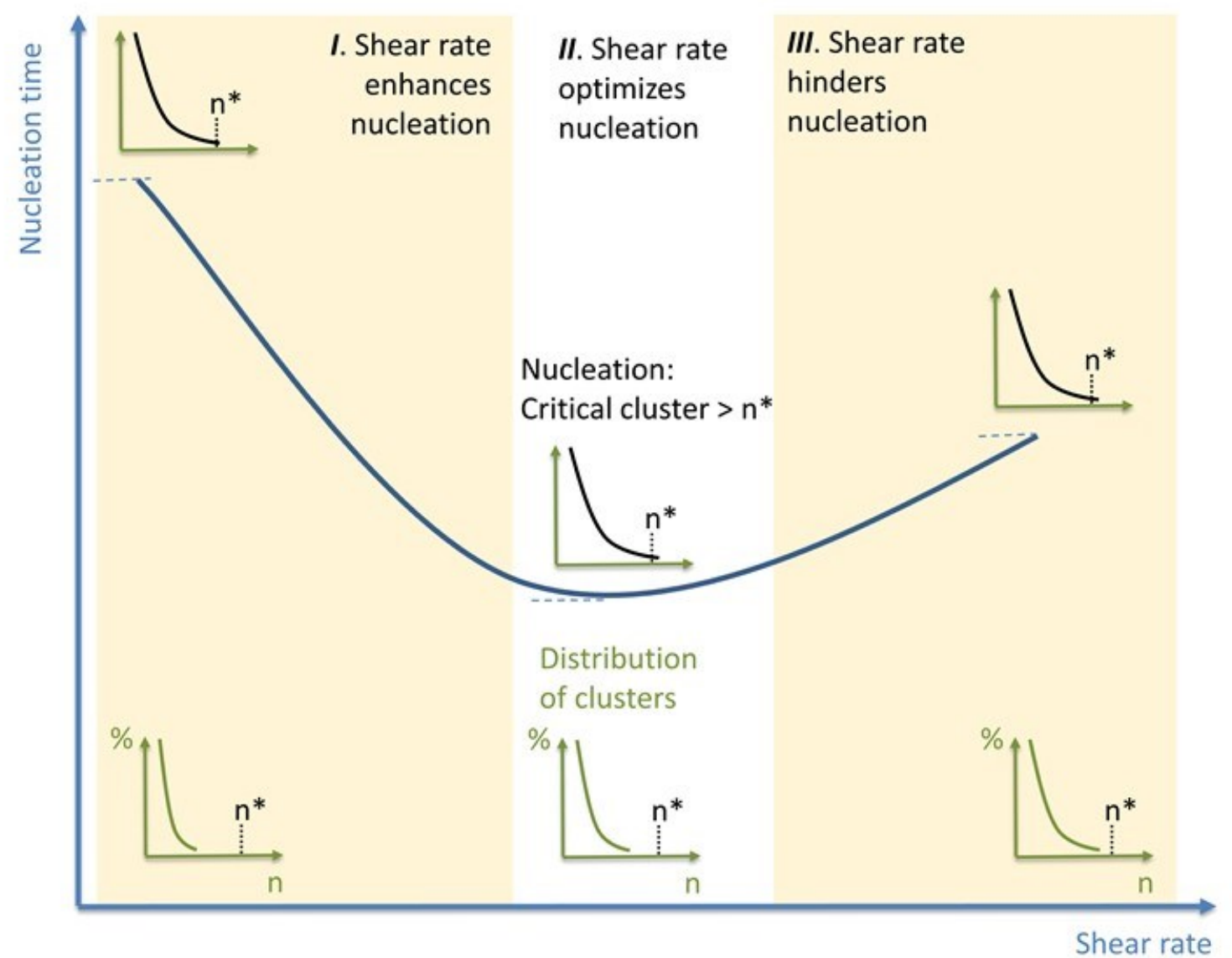

Figure 12 Schematic influence of shear rate on the induction time by effecting the distribution of the clusters 
CNT assumes a distribution of prenucleation molecular clusters spanning single molecules, $n$ $=1$, to critical nuclei, $n^{*}$. During nucleation the chemical potential drives the growth of clusters through coalescence and addition to form a stable nucleus ( $n^{*}$ ) [49]. Molecular dynamics simulations show that average shear rate can change the size distribution of molecular clusters in solution and both enhance or suppress the nucleation rate depending on the value [50]. Many experimental studies and simulations reported that an increase in the shear rate leads to the decrease in size distribution of particles in the solution [51-54]. In terms of explaining the observed nucleation kinetics for butyl paraben, at low shear rates (Region I, Figure 12) molecular clusters grow relatively slowly with the cluster size distribution taking comparatively longer for $n^{*}$ clusters to emerge compared with higher shear rates. In Region II (Figure 12) the highest nucleation rates are observed, with the rate of change of the cluster size distribution at a maximum. Further increases in shear rate take the system away from the minimum in nucleation time (Region III). This suppression in growth rate of the clusters may be due to the fact that larger clusters approaching $\mathrm{n}^{*}$ are now disrupted. Hence shear enhances nucleation rate overall, with all values greater than no shear, but that beyond the optimum value where growth of clusters towards $n^{*}$ is at a maximum, shear rate can remove some of the larger clusters, biasing the distribution towards lower values of $n$.

The CFD simulation indicates that spatial symmetry of the shear rate distributions in individual cells of the OFCs is retained independent of the length of reactor used (i.e. the number of glass straights used). For each glass column the shear rate distributions are equal and depend only on the oscillatory conditions and solution properties. Theoretically therefore the shear rate distribution is readily predicted for different lengths of reactor 
based on the conditions in a single glass column. The consistency of the simulated increase in shear rate between the MFOBC and COFC is supported by the reduced experimental induction time results at equivalent driving force. In a stirred tank however, the shear rate distributions are more complex upon scale up. Therefore, the OFC platform shows relative simplicity in scaling up from small scale nucleation experiments in a MFOBC for example to deliver consistent performance in a larger length COFC $[18,55]$.

\section{Conclusions}

Induction time measurements and simulated shear rate distributions are reported for the first time in an OFC. The nucleation kinetics for butyl paraben in ethanol show a strong dependency on the process conditions, specifically oscillation amplitude, frequency and net flow. The CFD simulations provide an explanation for the differences in experimental induction times observed, highlighting the importance of changes in flow on the resultant shear rate distribution. As expected, the highest shear rate appears in close proximity with the baffles in both OFC configurations tested. Critically the simulations inform the interpretation of variation in induction times as a function of shear rate. This attributes to the impact of shear rate on the dynamics of prenucleation cluster growth in the context of CNT. For equivalent power densities, increasing amplitude or reducing frequency leads to shorter induction times. The simulation and experimental results show consistency between batch MFOBC and COFC and stronger influence of increasing the amplitude than increasing the net flow. The addition of net flow in COFC is shown to decrease the induction time by increasing the pre-exponential factor in both homogeneous and heterogeneous nucleation regimes due to an increase in the average shear rate. Nucleation behaviours under various shear conditions show that the observed nucleation rates go through a maximum as shear 
rate increases. For butyl paraben, which shows a relatively narrow metastable zone width in ethanol, the ability to control and optimise nucleation rates in oscillatory flow opens the potential to exploit OFCs to control primary nucleation for the design of continuous crystallisation processes. Moreover the results provide a rational basis for the conversion of batch OFC crystallisation to a continuous OFC through the detailed understanding of the influence of net flow on nucleation.

\section{Notations}

\begin{tabular}{|c|c|c|}
\hline$A$ & Pre-exponential factor & {$\left[\mathrm{s}^{-1} \cdot \mathrm{m}^{-3}\right]$} \\
\hline$A_{H E N}$ & Pre-exponential factor in heterogeneous nucleation & {$\left[\mathrm{s}^{-1} \cdot \mathrm{m}^{-3}\right]$} \\
\hline$A_{H O N}$ & Pre-exponential factor in homogeneous nucleation & {$\left[\mathrm{s}^{-1} \cdot \mathrm{m}^{-3}\right]$} \\
\hline$B^{M 01}$ & Slope of $\ln t_{\text {ind }}$ equation & {$\left[\mathrm{K}^{3}\right]$} \\
\hline$C_{S}$ & Smagorinsky constant, 0.2 & \\
\hline$D$ & Distance to the closest wall & [m] \\
\hline$f$ & Frequency & {$[\mathrm{Hz}]$} \\
\hline$J$ & Nucleation rate & {$\left[\right.$ number $\left.\cdot \mathrm{m}^{-3} \cdot \mathrm{s}^{-1}\right]$} \\
\hline$J_{H E N}$ & Nucleation rate in heterogeneous nucleation & {$\left[\right.$ number $\left.\cdot \mathrm{m}^{-3} \cdot \mathrm{s}^{-1}\right]$} \\
\hline JHEN & Nucleation rate in homogeneous nucleation & {$\left[\right.$ number $\left.\cdot \mathrm{m}^{-3} \cdot \mathrm{s}^{-1}\right]$} \\
\hline$k$ & Frequency & {$[\mathrm{Hz}]$} \\
\hline$K$ & Von Karman constant & \\
\hline$M$ & Molecular weight & {$\left[\mathrm{g} \cdot \mathrm{mol}^{-1}\right]$} \\
\hline$N_{A}$ & Avogadro constant, $6.022 \times 10^{23}$ & {$\left[\mathrm{~mol}^{-1}\right]$} \\
\hline$P$ & Pressure of liquid & {$\left[\mathrm{kg} \cdot \mathrm{m}^{-1} \cdot \mathrm{s}^{-2}\right]$} \\
\hline$Q$ & Net flow rate & {$\left[\mathrm{mL} \cdot \mathrm{min}^{-1}\right]$} \\
\hline$\tilde{r}_{c}$ & Critical nuclei radius & {$[\mathrm{nm}]$} \\
\hline$R$ & Gas constant, 8.3145 & {$\left[\mathrm{~J} \cdot \mathrm{mol}^{-1} \cdot \mathrm{K}^{-1}\right]$} \\
\hline $\mathrm{S}$ & Supersaturation & \\
\hline$S_{i j}$ & Rate-of-strain tensor for sub-scale. & {$\left[\mathrm{kg} \cdot \mathrm{m}^{-1} \cdot \mathrm{s}^{-2}\right]$} \\
\hline$t_{\text {ind }}$ & Induction time of nucleation & \\
\hline$t$ & Piston movement time & \\
\hline$T$ & Temperature & {$[\mathrm{K}$} \\
\hline$T_{V}$ & A period of piston velocity & \\
\hline$V$ & Solution volume & {$\left[\mathrm{m}^{3}\right]$} \\
\hline$v_{m}$ & Molecular volume & {$\left[\mathrm{m}^{3}\right]$} \\
\hline$x$ & Actual solute molar fraction solubility & {$\left[\mathrm{mol} \cdot \mathrm{mol}^{-1}\right.$ total $]$} \\
\hline$x_{0}$ & Amplitude & [mm] \\
\hline$x^{*}$ & Equilibrium solute molar fraction solubility & {$\left[\mathrm{mol} \cdot \mathrm{mol}^{-1}\right.$ total $]$} \\
\hline$z_{p}$ & Velocity of piston & {$[\mathrm{m} \cdot \mathrm{s}-$} \\
\hline$\lambda_{l}$ & Bulk viscosity of liquid & {$[\mathrm{p}$} \\
\hline$\gamma$ & Activity coefficient of interfacial energy & \\
\hline$\sigma$ & Solid-liquid interfacial energy & {$\left[\mathrm{mJ} \bullet \mathrm{m}^{-2}\right]$} \\
\hline$\sigma_{H O N}$ & Interfacial energy in homogeneous nucleation & {$\left[\mathrm{mJ} \cdot \mathrm{m}^{-2}\right]$} \\
\hline$\sigma_{H E N}$ & Interfacial energy in heterogeneous nucleation & {$\left[\mathrm{mJ} \bullet \mathrm{m}^{-2}\right]$} \\
\hline & 3.1416 & \\
\hline
\end{tabular}




$\begin{array}{llr}\mu_{t} & \text { Subgrid-scale turbulent viscosity } & {\left[\mathrm{kg} \cdot \mathrm{m}^{-1} \cdot \mathrm{s}^{-1}\right]} \\ u_{z} & \text { Position of the piston } & \\ \rho_{l} & \text { Density of liquid } & {\left[\mathrm{kg}^{-} \mathrm{m}^{-3}\right]} \\ \tau_{k k} & \text { Isotropic part of the subgrid-scale stresses } & {\left[\mathrm{kg} \cdot \mathrm{m}^{-1} \cdot \mathrm{s}^{-2}\right]} \\ \delta_{i j} & \text { Kronecker delta function } & \\ \tau_{i j} & \text { Deviatoric part of the subgrid-scale stress tensor } & {\left[\mathrm{kg} \cdot \mathrm{m}^{-1} \cdot \mathrm{s}^{-2}\right]} \\ \mu_{l} & \text { Kinetic viscosity of the liquid } & {\left[\mathrm{m}^{2} \cdot \mathrm{s}^{-1}\right]} \\ \bar{S} & \text { Rate-of-strain for the resolved scale } & {\left[\mathrm{s}^{-1}\right]} \\ \vec{u}_{l} & \text { Velocity vector of liquid } & {\left[\mathrm{m}^{-1} \mathrm{~s}^{-1}\right]} \\ \overline{\bar{S}} & \text { Strain rate of liquid } & {\left[\mathrm{s}^{-1}\right]} \\ \overline{\bar{\tau}} & \text { Shear stress of liquid } & {\left[\mathrm{kg} \cdot \mathrm{m}^{-1} \cdot \mathrm{s}^{-2}\right]} \\ \vec{g} & \text { Gravity of liquid } & {\left[\mathrm{m}^{-2} \mathrm{~s}^{-2}\right]} \\ \bar{s}_{i j} & \text { Rate-of-strain tensor for the resolved scale } & {\left[\mathrm{kg} \cdot \mathrm{m}^{-1} \cdot \mathrm{s}^{-2}\right]} \\ \overline{\bar{I}} & \text { Unit vector } & \\ \bar{S}_{i j} & \text { Rate-of-strain tensor for the resolved scale } & {\left[\mathrm{s}^{-1}\right]} \\ \Delta & \text { local grid scale } & {[\mathrm{m}]} \\ \Delta G_{c} & \text { Critical free energy of nucleation } & {\left[\mathrm{kJ} \cdot \mathrm{mol}^{-1}\right]} \\ \Delta \mu & \text { Driving force of nucleation } & {\left[\mathrm{kJ} \cdot \mathrm{mol}^{-1}\right]} \\ \nabla \vec{u}_{l} & \text { Spatial derivative of velocity vector } & {\left[\mathrm{s}^{-1}\right]} \\ \left(\nabla \vec{u}_{l}\right)^{T} & \text { Transpose of } \nabla \overrightarrow{\mathrm{u}}_{1} & {\left[\mathrm{~s}^{-1}\right]}\end{array}$

\section{Acknowledgments}

We acknowledge the EPSRC Centre for Innovative Manufacturing in Continuous Manufacturing and Crystallisation for funding, grant ref: EP/I033459/1. Dr Xi Yu gratefully acknowledges the research fellowship from Leverhulme Trust and research grant (RPG-410).

\section{Reference}

1. Lawton, S., et al., Continuous crystallization of pharmaceuticals using a continuous oscillatory baffled crystallizer. Organic Process Research \& Development, 2009. 13(6): p. 1357-1363.

2. Schaber, S.D., et al., Economic analysis of integrated continuous and batch pharmaceutical manufacturing: a case study. Industrial \& Engineering Chemistry Research, 2011. 50(17): p. 10083-10092.

3. Baxendale, I.R., et al., Achieving Continuous Manufacturing: Technologies and Approaches for Synthesis, Workup, and Isolation of Drug Substance. May 20-21, 2014 Continuous Symposium. Journal of pharmaceutical sciences, 2014.

4. McGlone, T., et al., Oscillatory flow reactors (OFRs) for continuous manufacturing and crystallization. Organic Process Research \& Development, 2015.

5. Alvarez, A.J., A. Singh, and A.S. Myerson, Crystallization of cyclosporine in a multistage continuous MSMPR crystallizer. Crystal Growth \& Design, 2011. 11(10): p. 4392-4400.

6. Su, Q., Z.K. Nagy, and C.D. Rielly, Pharmaceutical crystallisation processes from batch to continuous operation using MSMPR stages: Modelling, design, and control. Chemical Engineering and Processing: Process Intensification, 2015. 89: p. 41-53. 
7. Lai, T.-T.C., et al., Control of Polymorphism in Continuous Crystallization via MSMPR Cascade Design. Crystal Growth \& Design, 2015.

8. Zhang, H., et al., Development of Continuous Anti-Solvent/Cooling Crystallization Process using Cascaded Mixed Suspension, Mixed Product Removal Crystallizers. Organic Process Research \& Development, 2012. 16(5): p. 915-924.

9. Ferguson, S., et al., Characterization of the anti-solvent batch, plug flow and MSMPR crystallization of benzoic acid. Chemical Engineering Science, 2013. 104: p. 44-54.

10. Ricardo, C. and N. Xiongwei, Evaluation and Establishment of a Cleaning Protocol for the Production of Vanisal Sodium and Aspirin Using a Continuous Oscillatory Baffled Reactor. Organic Process Research \& Development, 2009. 13(6): p. 1080-1087.

11. Lobry, E., et al., Liquid-liquid dispersion in a continuous oscillatory baffled reactorApplication to suspension polymerization. Chemical Engineering Journal, 2015. 259: p. 505518.

12. Sypek, K., et al., In Situ Monitoring of Stirring Effects on Polymorphic Transformations during Cooling Crystallization of Carbamazepine. Crystal Growth \& Design, 2012. 12(10): p. 48214828.

13. Cashell, C., D. Corcoran, and B. Hodnett, Control of polymorphism and crystal size of Lglutamic acid in the absence of additives. Journal of crystal growth, 2004. 273(1): p. 258-265.

14. Liu, J., M. Svärd, and Å.C. Rasmuson, Influence of Agitation and Fluid Shear on Nucleation of m-Hydroxybenzoic Acid Polymorphs. Crystal Growth \& Design, 2014. 14(11): p. 5521-5531.

15. Derksen, J., Numerical simulation of solids suspension in a stirred tank. AIChE Journal, 2003. 49(11): p. 2700-2714.

16. Hartmann, H., J. Derksen, and H. Van den Akker, Macroinstability uncovered in a Rushton turbine stirred tank by means of LES. AIChE journal, 2004. 50(10): p. 2383-2393.

17. Wei, H., W. Zhou, and J. Garside, Computational fluid dynamics modeling of the precipitation process in a semibatch crystallizer. Industrial \& engineering chemistry research, 2001. 40(23): p. $5255-5261$.

18. Jian, H. and X. Ni, A Numerical Study on the Scale-Up Behaviour in Oscillatory Baffled Columns. Chemical Engineering Research and Design, 2005. 83(10): p. 1163-1170.

19. Manninen, M., et al., Evaluation of axial dispersion and mixing performance in oscillatory baffled reactors using CFD. Journal of Chemical Technology and Biotechnology, 2013. 88(4): p. 553-562.

20. Ni, X., H. Jian, and A.W. Fitch, Computational fluid dynamic modelling of flow patterns in an oscillatory baffled column. Chemical Engineering Science, 2002. 57(14): p. 2849-2862.

21. Hossaini, A., J.J. Larsen, and J.C. Larsen, Lack of oestrogenic effects of food preservatives (parabens) in uterotrophic assays. Food and Chemical Toxicology, 2000. 38(4): p. 319-323.

22. Charnock, C. and T. Finsrud, Combining esters of para-hydroxy benzoic acid (parabens) to achieve increased antimicrobial activity. Journal of Clinical Pharmacy and Therapeutics, 2007. 32(6): p. 567-572.

23. Yang, H.Y. and A.C. Rasmuson, Nucleation of Butyl Paraben in Different Solvents. Crystal Growth \& Design, 2013. 13(10): p. 4226-4238.

24. Yang, H.Y., J. Thati, and A.C. Rasmuson, Thermodynamics of molecular solids in organic solvents. Journal of Chemical Thermodynamics, 2012. 48(0): p. 150-159.

25. Yang, H.Y. and A.C. Rasmuson, Solubility of Butyl Paraben in Methanol, Ethanol, Propanol, Ethyl Acetate, Acetone, and Acetonitrile. Journal of Chemical and Engineering Data, 2010. 55(11): p. 5091-5093.

26. Yang, H. and Å.C. Rasmuson, Investigation of Batch Cooling Crystallization in a Liquid-Liquid Separating System by PAT. Organic Process Research \& Development, 2012. 16(6): p. 12121224.

27. Yang, H.Y., H. Chen, and A.C. Rasmuson, Sandwich crystals of butyl paraben. Crystengcomm, 2014. 16(37): p. 8863-8873. 
28. Yang, H.Y., et al., Influence of Solvent and Solid-State Structure on Nucleation of Parabens. Crystal Growth \& Design, 2014. 14(8): p. 3890-3902.

29. Brandel, C. and J.H. ter Horst, Measuring induction times and crystal nucleation rates. Faraday discussions, 2015.

30. Davey, R.J., K.R. Back, and R.A. Sullivan, Crystal nucleation from solutions - transition states, rate determining steps and complexity. Faraday Discussions, 2015.

31. Mullin, J.W., Crystallization. 2001: Butterworth-Heinemann.

32. $\mathrm{Yu}, \mathrm{X}$., et al., A CFD study of biomass pyrolysis in a downer reactor equipped with a novel gas-solid separator-II thermochemical performance and products. Fuel Processing Technology, 2015. 133: p. 51-63.

33. $\mathrm{Yu}, \mathrm{X}$., et al., A CFD study of biomass pyrolysis in a downer reactor equipped with a novel gas-solid separator-l: Hydrodynamic performance. Fuel processing technology, 2014. 126: p. 366-382.

34. Yang, H., Relation between metastable zone width and induction time of butyl paraben in ethanol. CrystEngComm, 2015. 17(3): p. 577-586.

35. Liu, J. and Å.C. Rasmuson, Influence of agitation and fluid shear on primary nucleation in solution. Crystal Growth \& Design, 2013. 13(10): p. 4385-4394.

36. Howes, T., M. Mackley, and E. Roberts, The simulation of chaotic mixing and dispersion for periodic flows in baffled channels. Chemical engineering science, 1991. 46(7): p. 1669-1677.

37. Sobey, I.J., Oscillatory flows at intermediate Strouhal number in asymmetric channels. Journal of Fluid Mechanics, 1982. 125: p. 359-373.

38. Kubota, N., Effect of sample volume on metastable zone width and induction time. Journal of Crystal Growth, 2012. 345(1): p. 27-33.

39. Kadam, S.S., et al., A new view on the metastable zone width during cooling crystallization. Chemical Engineering Science, 2012. 72: p. 10-19.

40. Mealey, D., D.M. Croker, and A. Rasmuson, Crystal nucleation of salicylic acid in organic solvents. CrystEngComm, 2015.

41. Soos, M., et al., Effect of shear rate on aggregate size and morphology investigated under turbulent conditions in stirred tank. Journal of Colloid and Interface Science, 2008. 319(2): p. 577-589.

42. Kobari, M., N. Kubota, and I. Hirasawa, Secondary nucleation-mediated effects of stirrer speed and growth rate on induction time for unseeded solution. CrystEngComm, 2012. 14(16): p. 5255-5261.

43. Fouissac, E., M. Milas, and M. Rinaudo, Shear-rate, concentration, molecular weight, and temperature viscosity dependences of hyaluronate, a wormlike polyelectrolyte. Macromolecules, 1993. 26(25): p. 6945-6951.

44. Kulkarni, S.A., H. Meekes, and J.H. Ter Horst, Polymorphism control through a single nucleation event. Crystal Growth \& Design, 2014. 14(3): p. 1493-1499.

45. Liang, K., et al., An examination into the effect of stirrer material and agitation rate on the nucleation of L-glutamic acid batch crystallized from supersaturated aqueous solutions. Crystal growth \& design, 2004. 4(5): p. 1039-1044.

46. Mullin, J. and K. Raven, Nucleation in agitated solutions. 1961.

47. Mullin, J. and K. Raven, Influence of mechanical agitation on the nucleation of some aqueous salt solutions. Nature, 1962. 195: p. 35-38.

48. Allen, R.J., et al., Homogeneous nucleation under shear in a two-dimensional Ising model: Cluster growth, coalescence, and breakup. The Journal of chemical physics, 2008. 129(13): p. 134704.

49. Kashchiev, D., Nucleation: basic theory with applications. 2000: Butterworth-Heinemann.

50. Mokshin, A.V., B.N. Galimzyanov, and J.-L. Barrat, Extension of classical nucleation theory for uniformly sheared systems. Physical Review E, 2013. 87(6): p. 062307. 
51. Blandin, A., et al., Agglomeration in suspension of salicylic acid fine particles: influence of some process parameters on kinetics and agglomerate final size. Powder technology, 2003. 130(1): p. 316-323.

52. Gaaloul, S., M. Corredig, and S.L. Turgeon, The effect of shear rate on the molecular mass distribution of heat-induced aggregates of mixtures containing whey proteins and $\mathrm{K}$ carrageenan. Food biophysics, 2009. 4(1): p. 13-22.

53. Bałdyga, J., et al., Break up of nano-particle clusters in high-shear devices. Chemical Engineering and Processing: Process Intensification, 2007. 46(9): p. 851-861.

54. Spicer, P.T., et al., Effect of shear schedule on particle size, density, and structure during flocculation in stirred tanks. Powder Technology, 1998. 97(1): p. 26-34.

55. Smith, K. and M. Mackley, An experimental investigation into the scale-up of oscillatory flow mixing in baffled tubes. Chemical Engineering Research and Design, 2006. 84(11): p. 10011011. 
For Table of Contents Use Only

\section{The effect of oscillatory flow on nucleation kinetics of butyl paraben}

Huaiyu Yang, Xi Yu, Vishal Raval, Yassir Makkawi, Alastair Florence

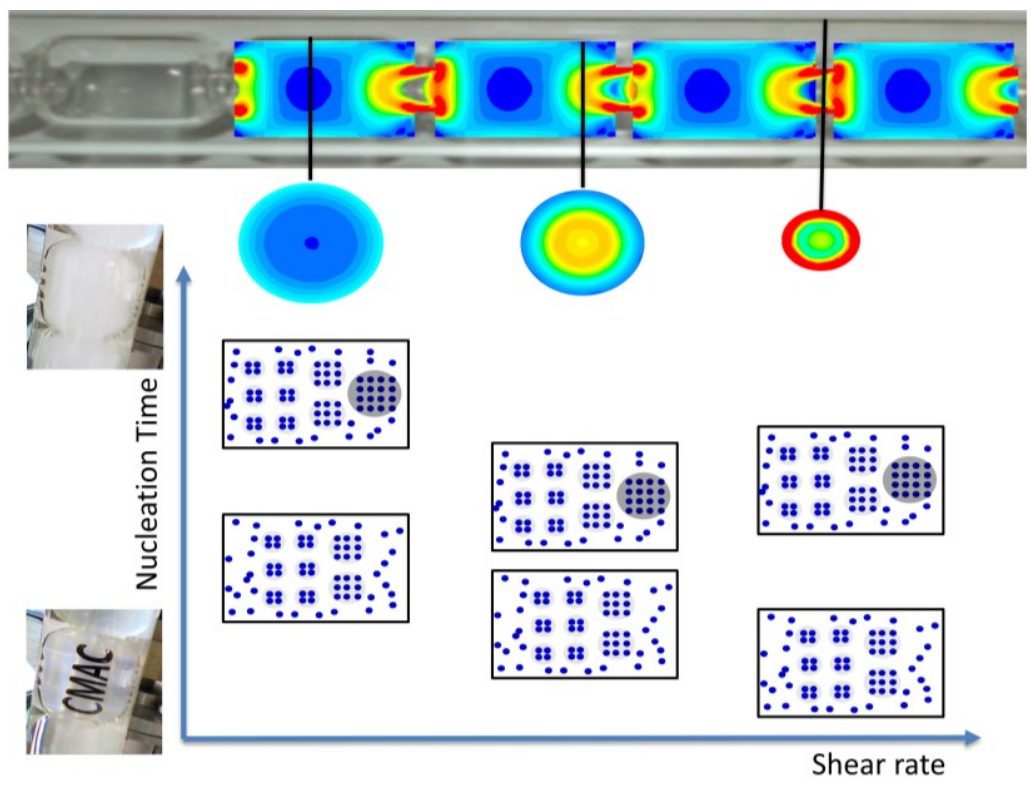

Nucleation behaviours of butyl paraben - ethanol solution in oscillatory flow crystallizers (OFC) with various amplitudes, frequencies and net pumping flow Spatial distributions of the shear rate by CFD simulation inside OFCs Maximum nucleation rate with increasing shear rate, due to the influence on the cluster distribution before nucleation

Providing a rational basis for the conversion of batch OFC crystallisation to a continuous OFC 